\title{
Avaliação de desempenho ambiental com base nos conceitos da produção mais limpa: uma análise sobre três propostas metodológicas (SAPmaisL, Índice P+L e IDRSI)
}

\section{Alexandre Borges Fagundes alexandre.fagundes@udesc.b Universidade do Estado de Santa Catarina (UDESC), São Bento do Sul, SC Brasil \\ Fernanda Hänsch Beuren fernanda.beuren@udesc.br \\ Universidade do Estado de Santa Catarina (UDESC), São Bento do Sul, SC, Brasil \\ Delcio Pereira \\ delcio.pereira@udesc.br \\ Universidade do Estado de Santa Catarina (UDESC), São Bento do Sul, SC Brasil \\ Moacyr Carlos Possan Junior moacyr.possan@udesc.br Universidade do Estado de Santa Catarina (UDESC), São Bento do Sul, SC Brasil \\ Débora Barni de Campos deborabarni@gmail.com \\ Universidade do Estado de Santa Catarina (UDESC), São Bento do Sul, SC, Brasil}

\begin{abstract}
RESUMO
Neste artigo analisam-se três propostas metodológicas de Avaliação de Desempenho Ambiental: o SAPmaisL (Sistema de Avaliação de Desempenho Ambiental com base nos conceitos de Produção mais Limpa), o Índice $P+L$ (Índice de Produção mais Limpa para a Indústria de Transformação do Estado de Minas Gerais) e o IDRSI (Índice de Destinação dos Resíduos Sólidos Industriais). As metodologias são contextualizadas no cenário dos desafios das organizações industriais em se adequar às determinações legais envolvendo os processos produtivos e o meio ambiente. Destacam-se as premissas da Política Nacional de Resíduos Sólidos e da Produção mais Limpa, pois são também ferramentas de apoio ao gerenciamento dos resíduos industriais de forma alinhada às determinações da referida Lei. O objetivo da pesquisa foi ampliar o entendimento acerca dessas metodologias a partir das discussões elencadas, embasando um senso crítico a gestores, pesquisadores e afins, dando subsídios à escolha/elaboração de mecanismos para o gerenciamento de resíduos em empreendimentos industriais sob a perspectiva da ecoeficiência, contribuindo, dessa maneira, para a melhoria do meio ambiente e fomentando o desenvolvimento sustentável para a indústria. Conclui-se que, apesar de suas diferenças, as metodologias pesquisadas são complementares e flexíveis, permitindo às empresas obter suporte para tomadas de decisão quanto a condução de seus processos produtivos com base nos conceitos da Produção mais Limpa.
\end{abstract}

PALAVRAS-CHAVE: Produção mais limpa. Avaliação de desempenho ambiental. Indicadores. Resíduos sólidos industriais. Política nacional de resíduos sólidos. 


\section{INTRODUÇÃO}

Ações no sentido do aumento da competitividade e produtividade são, continuamente, foco de atenção dos setores produtivos visando impactar positivamente na sobrevivência das empresas, em nível micro, e no crescimento da economia do país, em nível macro. Adicionalmente, visando o desenvolvimento sustentado, determinações legais envolvendo processos fabris e as interações com o meio ambiente configuram-se como importantes variáveis intervenientes (FIESP/CIESP, 2004).

Nessa conjuntura, o advento da Política Nacional de Resíduos Sólidos (PNRS) trouxe grande incentivo à melhoria do meio ambiente no país e, simultaneamente, grandes desafios à sociedade (sobretudo aos empreendimentos industriais, geradores de resíduos sólidos), no sentido da necessidade de adequação aos procedimentos preconizados pela nova Lei (FAGUNDES et al., 2016).

Considerando sua aplicação acerca das organizações industriais, a PNRS traz como principais objetivos: estimular o emprego de padrões sustentáveis de produção e consumo de bens e serviços; adotar, desenvolver e aprimorar tecnologias limpas visando a minimização de impactos ambientais; reduzir a periculosidade e o volume dos resíduos considerados perigosos; incentivar a indústria da reciclagem e a gestão integrada dos resíduos sólidos; a gestão dos resíduos conforme a sequência de priorização preconizada (não geração, redução, reutilização, reciclagem, tratamento dos resíduos sólidos e disposição final ambientalmente adequada dos rejeitos), bem como incentivar o desenvolvimento de sistemas de gestão ambiental empresarial (FIESP, 2012).

Observa-se, portanto, que a PNRS engloba importantes determinações a fim de promover o melhor gerenciamento dos resíduos industriais. Nesse sentido, levando em conta a possibilidade de utilização de ferramentas de apoio ao gerenciamento dos resíduos industriais, em consonância com a PNRS, esta pesquisa se dedicou à análise de três propostas metodológicas que tem em comum a aplicação de conceitos de Produção mais Limpa para a Avaliação de Desempenho Ambiental das operações industriais: o SAPmaisL (Sistema de Avaliação de Desempenho Ambiental com base nos conceitos de Produção mais Limpa), o Índice P+L (Índice de Produção mais Limpa para a Indústria de Transformação do Estado de Minas Gerais) e o IDRSI (Índice de Destinação dos Resíduos Sólidos Industriais).

Assim, a presente pesquisa discorre sobre questões bastante relevantes, envolvendo a descrição das metodologias; abordagem e percentuais de importância dos aspectos ambientais e indicadores utilizados; dados de entrada; setores industriais abordados; prioridades, dificuldades, aplicabilidade, restrições, limitações e vantagens de cada metodologia; com o propósito de ampliar o entendimento acerca das mesmas, pretendendo também, a partir das discussões elencadas, embasar um senso crítico a gestores, pesquisadores e afins, dando subsídios à escolha/elaboração de mecanismos para o gerenciamento de resíduos em empreendimentos industriais, contribuindo para a melhoria do meio ambiente e, simultaneamente, fomentando o desenvolvimento sustentável da indústria nacional. 


\section{PRODUÇÃO MAIS LIMPA E AVALIAÇÃO DE DESEMPENHO AMBIENTAL}

A adoção de processos ecoeficientes permite às empresas auferir benefícios tais como aumento de competitividade e margem de lucro, redução de custos e riscos (BERTÉLI, BARCELLOS, BORELLA, 2013), minimização de impactos ambientais, bem como do uso de matérias-primas (GIANNETTI e ALMEIDA, 2006), produzindo mais bens (e/ou serviços) empregando menor quantidade de recursos naturais e gerando menos poluição (ALMEIDA, 2002; FEAM, 2009).

Dentre as ferramentas de gestão fundamentadas na ecoeficiência, a Produção mais Limpa $(\mathrm{P}+\mathrm{L})$ se destaca pela busca da solução dos problemas ambientais na origem, permitindo às empresas a criação de novas oportunidades de negócio (BERTÉLI e PESSIN, 2009), envolvendo aspectos econômicos e ambientais, baseados num sistema de busca pela melhoria contínua (FEAM, 2009), promovendo assim um ambiente favorável para a mudança organizacional (BERTÉLI, BARCELLOS, BORELLA, 2013) e sendo plenamente integrável a outros sistemas de gestão ambiental (VAZ, FAGUNDES, OLIVEIRA, 2009).

Produção mais Limpa pode ser definida como a aplicação contínua de uma estratégia técnica, econômica e ambiental associada às atividades de uma empresa (processos, produtos e serviços) a fim de aumentar a eficiência no uso de materiais e energia, assim eliminando/reduzindo resíduos, emissões e efluentes, bem como riscos ao homem e ao meio ambiente (CNTL, 2002, 2003a).

As ações de $\mathrm{P}+\mathrm{L}$ são classificadas em três níveis hierárquicos sequenciais, que envolvem desde a eliminação/redução da geração de resíduos na fonte, até a análise de oportunidades de reutilização/aproveitamento/reciclagem (em âmbito interno e externo à empresa) dos resíduos remanescentes. 0 monitoramento dos resultados se faz por meio da adoção de indicadores ambientais e de processo, a fim de se avaliar o desempenho das ações ao longo do tempo (CNTL, 2003a).

Nesse sentido, ressalta-se a importância da avaliação do desempenho ambiental no contexto empresarial, pois, no processo de comunicação, os indicadores têm por objetivo a agregação e quantificação de informações sobre fatos, muitas vezes, complexos (RAUPP, SELIG, SIERRA, 2015), auxiliando os tomadores de decisão no tange ao planejamento das ações (VAN BELLEN, 2006).

A avaliação de desempenho ambiental, portanto, se constitui como ferramenta de facilitação quanto aos processos decisórios acerca da eficiência do desempenho e da gestão ambiental da empresa (OLIVEIRA, BORGES e JABBOUR, 2005), possibilitando também a utilização de indicadores e índices como benchmarkings de boas práticas de sustentabilidade ambiental (TAUCHEN e BRANDLI, 2006).

Dessa forma, para que a avaliação de desempenho ambiental cumpra de maneira satisfatória os objetivos pretendidos, é de suma importância a escolha dos indicadores e índices mais adequados, também atentando - dentre outras considerações - aos critérios ajuizados, relevância, disponibilidade e forma de obtenção dos dados (FAGUNDES, SILVA, MELLO, 2015). 


\section{METODOLOGIAS DE AVALIAÇÃO DE DESEMPENHO AMBIENTAL COM BASE NOS CONCEITOS DE PRODUÇÃO MAIS LIMPA}

Neste tópico são apresentadas três metodologias de Avaliação de Desempenho Ambiental que tem em comum o alinhamento aos conceitos de $\mathrm{P}+\mathrm{L}$ : SAPmaisL, Índice P+L e IDRSI.

\section{SAPMAISL}

De acordo com Neetzow, Oliveira e Souza (2009), face aos diferentes enfoques e variações no que concerne à metodologia de implementação apresentada por um crescente número de atores envolvidos com a promoção, capacitação e implementação de Produção mais Limpa, o estabelecimento de uma base comum para o monitoramento dessa implementação e verificação de resultados torna-se uma necessidade, que pode ser suprida por meio de um Sistema de Avaliação de Desempenho Ambiental que faça uso dos conceitos de $\mathrm{P}+\mathrm{L}$, e que verifique o nível de avanço das empresas com relação à aplicação destes conceitos: o SAPmaisL.

O SAPmaisL (Sistema de Avaliação de Desempenho Ambiental com base nos conceitos de Produção mais Limpa) foi desenvolvido pelo SENAI Departamento Nacional, sob a Coordenação técnica do CNTL - Centro Nacional de Tecnologias Limpas (COELHO et al., 2009) visando, em empresas que já fazem uso da metodologia de $\mathrm{P}+\mathrm{L}$ desenvolvida pelo UNIDO/UNEP, implantar opções de $\mathrm{P}+\mathrm{L}$, monitorando seus indicadores e sua melhoria contínua (COELHO et al., 2009; NEETZOW, OLIVEIRA e SOUZA, 2009), seguindo as 16 etapas apresentadas no Quadro 1.

Quadro 1 - Etapas de aplicação do SAPmaisL

\begin{tabular}{|c|c|}
\hline Etapas & Ações \\
\hline 1 & Promover uma pré-avaliação de empresas para aderir ao SAPmaisL; \\
\hline 2 & $\begin{array}{l}\text { Realizar o diagnóstico ambiental da empresa, por meio da identificação dos } \\
\text { processos produtivos gerando um Diagrama de Blocos com as entradas e } \\
\text { saídas de cada operação realizada; }\end{array}$ \\
\hline 3 & $\begin{array}{c}\text { Identificar os aspectos e impactos ambientais, econômicos e sociais da } \\
\text { organização; }\end{array}$ \\
\hline 4 & $\begin{array}{c}\text { Definir os aspectos ambientais e os respectivos indicadores de desempenho } \\
\text { operacional que serão monitorados, pelo período de três anos, conforme a } \\
\text { meta escolhida e o plano de ação, acordados entre as partes; }\end{array}$ \\
\hline 5 & $\begin{array}{l}\text { Definir as metas a serem alcançadas (números a serem atingidos) ao final de } \\
\text { seis meses; }\end{array}$ \\
\hline 6 & $\begin{array}{l}\text { Compilar os dados associando-os aos valores de investimento necessários } \\
\text { para atendimento às metas a serem alcançadas; }\end{array}$ \\
\hline 7 & $\begin{array}{l}\text { Determinar retorno financeiro com base em cada investimento feito para } \\
\text { alcançar a meta de cada indicador; }\end{array}$ \\
\hline 8 & Preencher Ficha de Avaliação de Desempenho em P+L; \\
\hline 9 & $\begin{array}{c}\text { Preencher a Ficha de Indicador, que contém o nome do indicador, cronologia } \\
\text { de monitoramento, justificativa de escolha, memorial de cálculo, } \\
\text { equipamentos e/ou métodos de medição e calibração; }\end{array}$ \\
\hline 10 & $\begin{array}{l}\text { Realizar o primeiro monitoramento, e promover um acompanhamento junto } \\
\text { à organização, orientando e monitorando o desempenho, conforme as metas }\end{array}$ \\
\hline
\end{tabular}




\begin{tabular}{|c|c|}
\hline & estabelecidas; \\
\hline 11 & $\begin{array}{l}\text { Medir todos os parâmetros necessários de cada indicador pelo período de } \\
\text { seis meses; }\end{array}$ \\
\hline 12 & $\begin{array}{c}\text { Preencher a Ficha de Avaliação de Desempenho em } \mathrm{P}+\mathrm{L} \text { (com os seis meses } \\
\text { de medições dos indicadores), com justificativas e evidências do atendimento } \\
\text { às metas; }\end{array}$ \\
\hline 13 & Submeter a empresa à avaliação realizada por especialistas; \\
\hline 14 & Recomendar a empresa à certificação de aprovação no SAPmaisL; \\
\hline 15 & $\begin{array}{l}\text { Fornecer o certificado de aprovação SAPmaisL e o Selo } P+L \text {, após validação da } \\
\text { recomendação, estabelecer critérios de melhoria contínua e permitir a } \\
\text { divulgação pública dos índices dos indicadores alcançados (divulgar os } \\
\text { resultados); }\end{array}$ \\
\hline 16 & $\begin{array}{c}\text { Monitorar a cada ano (por mais dois anos) após a entrega do Certificado de } \\
\text { Desempenho Ambiental, todos os indicadores determinados e os novos } \\
\text { incluídos verificando se as metas continuam a ser alcançadas para manter o } \\
\text { Certificado. }\end{array}$ \\
\hline
\end{tabular}

Fonte: Adaptado de COELHO et al. (2009); NEETZOW, OLIVEIRA e SOUZA (2009)

O SAPmaisL aborda 11 aspectos ambientais, contemplando a sustentabilidade da água, de matérias-primas, de insumos e de energia (NEETZOW, 2010), não havendo hierarquização pré-definida de importância entre os aspectos ambientais (e/ou indicadores) elencados, pois essa escolha depende das demandas de cada empresa. A Figura 1 apresenta os aspectos ambientais abordados pelo SAPmaisL, além de considerações sobre seus indicadores.

Figura 1 - Disposição esquemática do SAPmaisL (aspectos ambientais e indicadores)

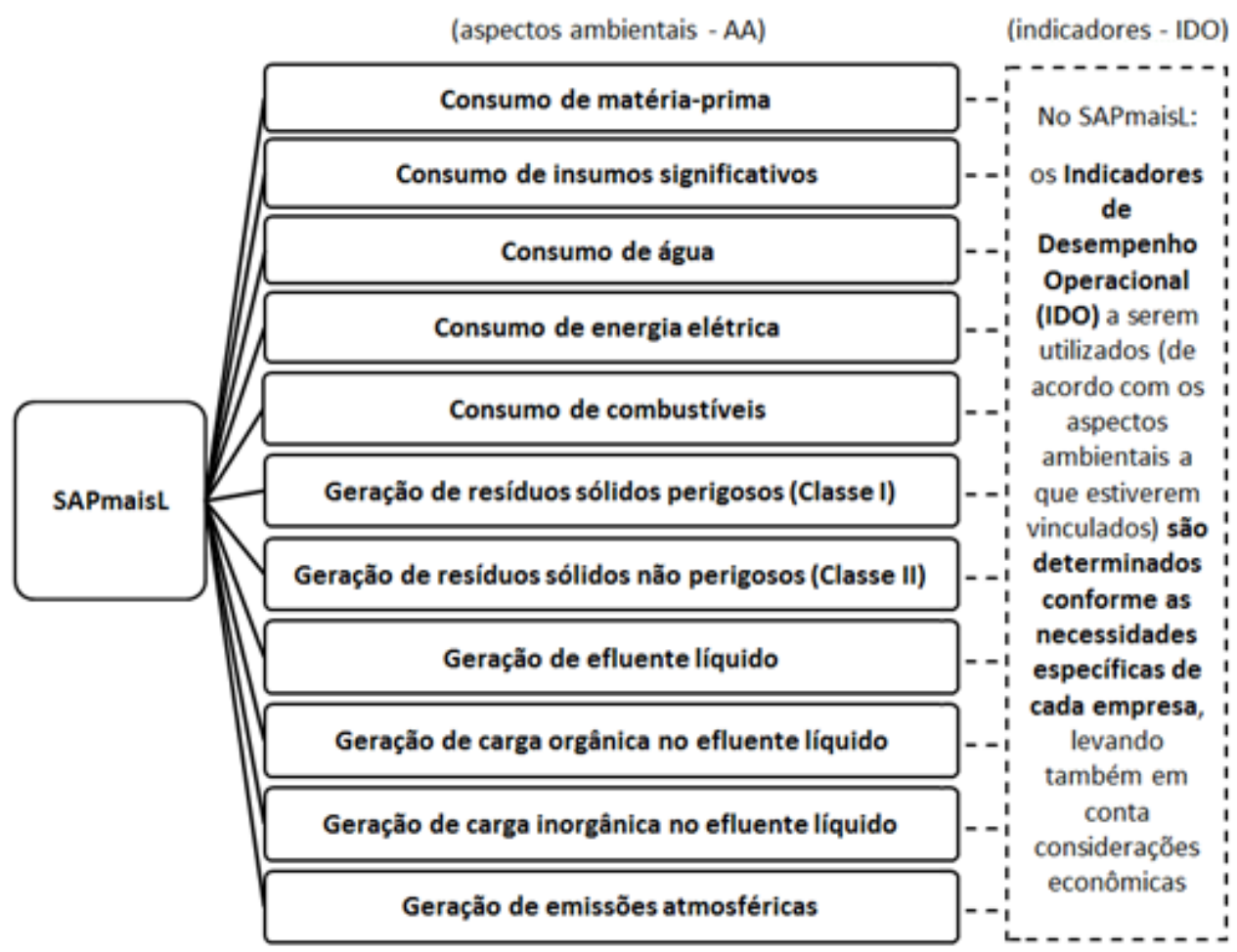

Fonte: Adaptado de Coelho et al. (2009), Neetzow (2010) 
De acordo com CNTL (2003b, p.1), "a implantação de sistemas de gestão ambiental e de técnicas que visem a produção mais limpa nas empresas está principalmente relacionada à eficiência no processo produtivo, sendo medidas em termos de recursos financeiros economizados em relação ao investimento realizado", assim reduzindo os custos de produção e, simultaneamente, a degradação ambiental. Dessa forma, devem ser associados indicadores de eficiência no processo produtivo e indicadores ambientais.

Nesse contexto, de acordo com a norma ABNT NBR ISO 14031:2004 (ABNT, 2004), os indicadores que "fornecem informações sobre o desempenho ambiental das operações da organização" são os chamados Indicadores de Desempenho Operacional (IDO). O Quadro 2 apresenta alguns aspectos ambientais e indicadores pertinentes, relacionados aos processos produtivos, com suas respectivas métricas.

Quadro 2 - Produção mais Limpa: exemplos de Indicadores de Desempenho Operacional (IDO)

\begin{tabular}{|c|c|c|c|}
\hline & Nome & Composição do indicador & Unidade \\
\hline 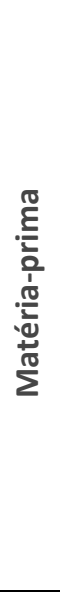 & $\begin{array}{l}\text { - Consumo total de matérias- } \\
\text { primas; } \\
\text { - Eficiência do uso de } \\
\text { matérias-primas; } \\
\text { - Total de embalagens; } \\
\text { - Proporção de embalagem; } \\
\text { - Proporção de embalagens } \\
\text { reutilizáveis; } \\
\text { - Entradas de matérias- } \\
\text { primas perigosas; } \\
\text { - Proporção de matérias- } \\
\text { primas renováveis. }\end{array}$ & $\begin{array}{c}\text { Absoluto } \\
\text { Total de matérias- } \\
\text { primas/Produto final } \\
\text { Absoluto } \\
\text { Total de embalagens/Produto } \\
\text { final } \\
\text { Embalagens reutilizáveis/Total } \\
\text { de embalagens } \\
\text { Absoluto } \\
\text { Total de matérias-primas } \\
\text { renováveis/Total de matérias- } \\
\text { primas }\end{array}$ & $\begin{array}{l}\text { (kg) ou (t) } \\
\text { (\%) ou (kg/kg) } \\
(\mathrm{kg}) \text { ou }(\mathrm{t}) \\
(\%) \text { ou }(\mathrm{kg} / \mathrm{kg}) \\
(\%) \text { ou }(\mathrm{kg} / \mathrm{kg}) \\
(\mathrm{kg}) \text { ou }(\mathrm{t}) \\
(\%) \text { ou }(\mathrm{kg} / \mathrm{kg})\end{array}$ \\
\hline & $\begin{array}{l}\text { - Consumo total de energia; } \\
\text { - Consumo específico de } \\
\text { energia; } \\
\text { - Intensidade energética; } \\
\text { - Cota de energia renovável. }\end{array}$ & $\begin{array}{c}\text { Absoluto } \\
\text { Consumo total de } \\
\text { energia/Produto final } \\
\text { Consumo num } \\
\text { processo/Consumo total de } \\
\text { energia } \\
\text { Entrada de energia } \\
\text { renovável/Consumo total de } \\
\text { energia }\end{array}$ & $\begin{array}{c}(\mathrm{kWh}) \\
(\mathrm{kWh} / \mathrm{kg}) \\
(\%) \\
(\%)\end{array}$ \\
\hline 疍 & $\begin{array}{l}\text { - Consumo total de água; } \\
\text { - Consumo específico; } \\
\text { - Intensidade de consumo; } \\
\text { - Taxa de reciclagem de } \\
\text { água; } \\
\text { - Taxa de reciclagem de água } \\
\text { em relação ao efluente. }\end{array}$ & $\begin{array}{c}\text { Absoluto } \\
\text { Consumo de água/Produto } \\
\text { final } \\
\text { Consumo num processo por } \\
\text { setor/Consumo total de água } \\
\text { Consumo de água reciclada } \\
\text { Consumo de água } \\
\text { reciclada/Geração total de } \\
\text { efluentes }\end{array}$ & $\begin{array}{c}\begin{array}{c}\left(\mathrm{m}^{3}\right) \\
\left(\mathrm{m}^{3} / \mathrm{kg}\right)\end{array} \\
(\%) \text { ou }\left(\mathrm{m}^{3} / \mathrm{m}^{3}\right) \\
(\%) \text { ou }\left(\mathrm{m}^{3} / \mathrm{m}^{3}\right) \\
(\%) \text { ou }\left(\mathrm{m}^{3} / \mathrm{m}^{3}\right)\end{array}$ \\
\hline
\end{tabular}




\begin{tabular}{|c|c|c|c|}
\hline 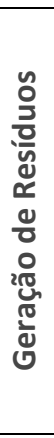 & $\begin{array}{l}\text { - Total de resíduos gerados; } \\
\text { - Geração específica sobre o } \\
\text { total; } \\
\text { - Resíduo para reciclagem; } \\
\text { - Resíduo para disposição; } \\
\text { - Percentual reciclado; } \\
\text { - Resíduo Classe I, II e III. }\end{array}$ & $\begin{array}{c}\text { Absoluto } \\
\text { Tipo de resíduo/Total de } \\
\text { produto } \\
\text { Absoluto } \\
\text { Absoluto } \\
\text { Resíduo reciclado/Total gerado } \\
\text { de resíduos } \\
\text { Montante de resíduo por } \\
\text { classe/Total gerado de } \\
\text { resíduos }\end{array}$ & $\begin{array}{c}(\mathrm{kg}) \\
(\mathrm{kg} / \mathrm{kg}) \\
(\mathrm{kg}) \\
(\mathrm{kg}) \\
(\%) \\
(\%)\end{array}$ \\
\hline 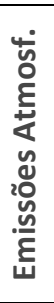 & $\begin{array}{c}\text { - Quantidade total de } \\
\text { emissões; } \\
\text { - Carga de emissão; } \\
\text { - Taxa de emissão; } \\
\text { - Carga relativa de emissões. }\end{array}$ & $\begin{array}{c}\text { Absoluto } \\
\text { CO2, NOX, vOC, particulados }{ }^{1} \\
\text { CO2, NOX,VOC, } \\
\text { particulados }{ }^{1} / \text { Total de } \\
\text { emissões } \\
\text { Carga de emissão/Produto }\end{array}$ & $\begin{array}{c}\left(\mathrm{m}^{3}\right) \\
(\mathrm{kg}) \\
(\%) \text { ou }(\mathrm{kg} / \mathrm{kg}) \\
\\
(\mathrm{kg} / \mathrm{kg})\end{array}$ \\
\hline 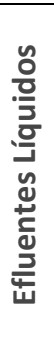 & $\begin{array}{c}\text { - Quantidade total de } \\
\text { efluentes; } \\
\text { - Geração de efluentes por } \\
\text { produção; } \\
\text { - Carga residual emitida²; } \\
\text { - Carga residual emitida } \\
\text { específica. }\end{array}$ & $\begin{array}{c}\text { Absoluto } \\
\text { Quantidade de } \\
\text { efluentes/Produto } \\
\text { Parâmetro considerado - } \\
\text { absoluto } \\
\text { Carga considerada }{ }^{3} / \text { Produto } \\
\text { final }\end{array}$ & $\begin{array}{c}\left(\mathrm{m}^{3}\right) \\
\left(\mathrm{m}^{3} / \mathrm{kg}\right) \\
(\mathrm{kg}) \\
(\mathrm{kg} / \mathrm{kg})\end{array}$ \\
\hline & $\begin{array}{l}\text { - Parcela de produtos com } \\
\text { certificação ambiental; } \\
\text { - Parcela de produtos com } \\
\text { matérias-primas } \\
\text { ambientalmente corretas; }\end{array}$ & $\begin{array}{l}\text { Quantidade dos produtos } \\
\text { certificados/Quantidade total } \\
\text { dos produtos } \\
\text { Quantidade dos produtos com } \\
\text { matérias-primas } \\
\text { ambientalmente } \\
\text { corretas/Quantidade total dos } \\
\text { produtos } \\
\text { Quantidade dos produtos de } \\
\text { materiais } \\
\text { reciclados/Quantidade total } \\
\text { dos produtos } \\
\text { Quantidade das embalagens } \\
\text { retornáveis/Quantidade total } \\
\text { de embalagens } \\
\text { Quantidade de } \\
\text { embalagens/Quantidade total } \\
\text { dos produtos }\end{array}$ & $(\mathrm{kg} / \mathrm{t})$ \\
\hline
\end{tabular}

${ }^{1}$ selecionados como parâmetros individuais e não como somatório de emissões;

${ }^{2}$ considerar cada parâmetro isoladamente, multiplicando pelo volume ou vazão de efluentes;

${ }^{3}$ considerar a carga residual individual ou total relacionada com o produto final. Fonte: Adaptado de CNTL (2003b)

Os dados solicitados (e/ou levantados junto às empresas), a princípio, são os que se referem à realização do diagnóstico ambiental da empresa, por meio da identificação dos processos produtivos e da análise dos fluxos de material e energia que entram e saem dos mesmos, gerando um Diagrama de Blocos com as entradas e saídas. As entradas são matérias primas, materiais auxiliares e 
energia, enquanto as saídas são subprodutos, resíduos, efluentes e emissões (CNTL, 2003c; COELHO et al., 2009; NEETZOW, OLIVEIRA e SOUZA, 2009).

De acordo com Neetzow, Oliveira e Souza (2009), as 23 empresas-piloto participantes do projeto englobaram sete setores distribuídos pelos cinco estados brasileiros participantes: Rio Grande do Sul (1- Madeira/mobiliário, 3-Metalmecânico, 1-Alimentos), Paraná (1-Metal-mecânico, 1-Tecnologia da informação, 1-Papel/gráfico e editorial, 1-Madeira/mobiliário), Rio de Janeiro (2-Químico, 1Papel/gráfico e editorial, 1-Alimentos, 2-Metal-mecânico), Minas Gerais (2Madeira/mobiliário, 1-Papel/gráfico e editorial, 1-Metal-mecânico), Bahia (1Químico, 1-Têxtil, 2-Metal-mecânico).

Dentre os 11 aspectos ambientais (AA) abordados pelo SAPmaisL, cada empresa poderia escolher três para serem monitorados por meio de indicadores de desempenho operacional (IDO), devendo haver no mínimo um indicador para cada aspecto escolhido. A cada ciclo de melhoria, as empresas deveriam identificar, no mínimo, três novos desafios, novos aspectos ambientais ou aprimorar os índices dos indicadores operacionais existentes (estabelecer novas metas). Se a opção fosse pela definição de novo aspecto ambiental, deveria haver comprovação da manutenção dos índices (durante cada ciclo) dos indicadores operacionais anteriores (NEETZOW, OLIVEIRA e SOUZA, 2009).

\section{ÍNDICE P+L}

O Índice P+L (Índice de Produção mais Limpa para a Indústria de Transformação do Estado de Minas Gerais) é um projeto vinculado à ação Otimização de Sistemas de Gestão Adequada de Resíduos Sólidos por Empreendimentos Geradores do Projeto Estruturador de Resíduos Sólidos, a cargo da FEAM (Fundação Estadual do Meio Ambiente).

$\mathrm{O}$ Índice $\mathrm{P}+\mathrm{L}$ visa incentivar e valorizar a adoção de práticas de $\mathrm{P}+\mathrm{L}$ nas atividades industriais, sendo um instrumento capaz de avaliar a evolução e a efetividade das ações implementadas em organizações industriais para a melhoria do desempenho ambiental das atividades potencialmente poluidoras ou degradadoras do meio ambiente (FEAM, 2009).

Faz-se uso de uma planilha eletrônica que viabiliza o cálculo automático do Índice $\mathrm{P}+\mathrm{L}$ após a inserção de determinadas informações.

São introduzidas informações referentes ao cálculo de 21 indicadores (valores componentes de cada indicador), a exemplo dos parâmetros de entrada (vide Quadro 4); bem como dos benchmarks (valores-padrão específicos estabelecidos para cada indicador/setor industrial) e valores alusivos à classificação do empreendimento quanto ao seu porte e potencial poluidor (de acordo com a Deliberação Normativa COPAM no 74/2004).

São tratados por meio de fórmulas matemáticas (envolvendo, entre outras, operações tais como normalizações e ponderações dos dados), resultando em valores referentes a cinco sub-índices (Materiais, Água, Energia, Resíduos Sólidos, Emissões Atmosféricas) e ao Índice P+L (FEAM, 2009).

$\mathrm{O}$ Índice $\mathrm{P}+\mathrm{L}$ corresponde a um número entre 0 e 1 (quanto mais próximo de 1 , melhor). 
Dessa forma, a metodologia oportuniza uma análise agregada ou desagregada dos cinco sub-índices, auxiliando os gestores no acompanhamento e definição de ações direcionadas às áreas mais deficitárias, resultando em uma melhoria global do Índice $\mathrm{P}+\mathrm{L}$ dos processos produtivos.

As esferas (ou sub-índices) nas quais o Índice $\mathrm{P}+\mathrm{L}$ foi dividido referem-se aos grandes campos em que são identificados os aspectos ambientais mais significativos nos empreendimentos da indústria de transformação (FEAM, 2009).

A Figura 2 apresenta a disposição esquemática do Índice $P+L$, seus subíndices, classificação e quantidade dos indicadores.

Figura 2 - Disposição esquemática do Índice P+L (índice, sub-índices, classificação e quantidade de indicadores)

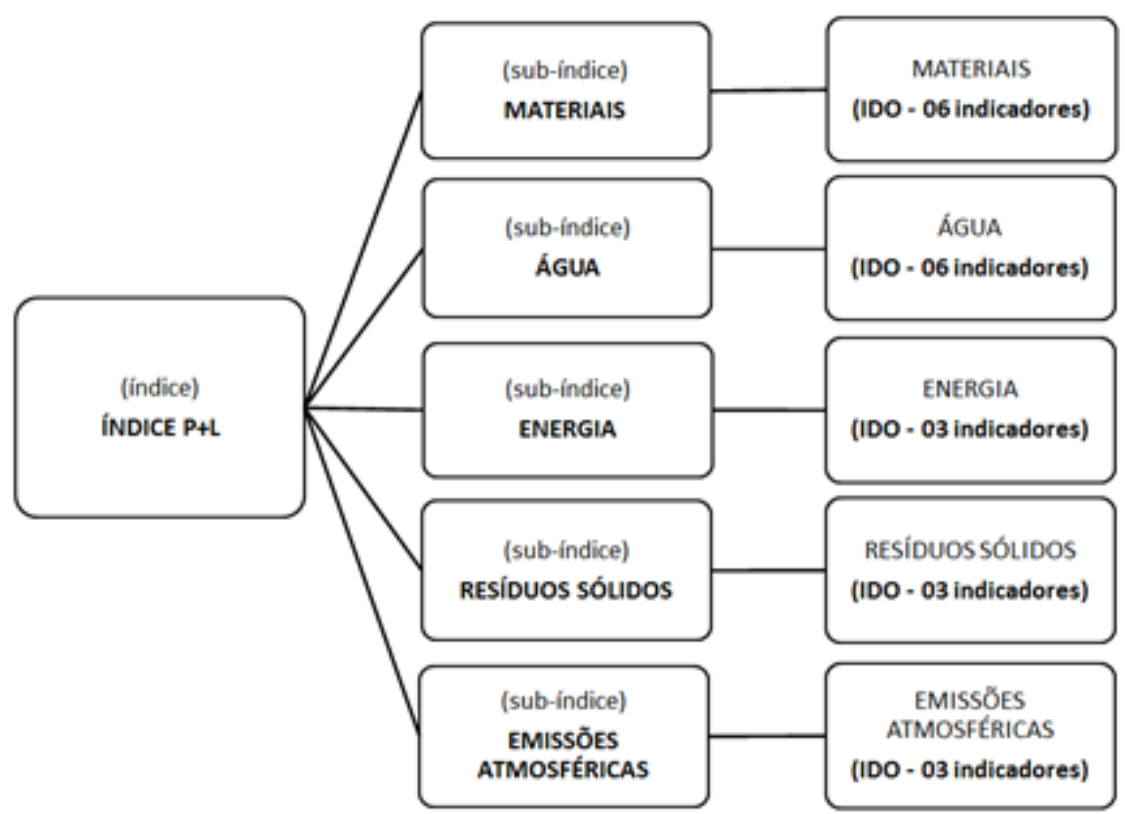

IDO: Indicador de Desempenho Operacional

Fonte: Adaptado de FEAM (2009)

De acordo com FEAM (2009), a escolha dos indicadores a serem utilizados na composição do Índice $\mathrm{P}+\mathrm{L}$ foi orientada pelas bases de indicadores usualmente empregadas em avaliações de $P+L$ nas empresas.

O Quadro 3 apresenta de maneira detalhada os sub-índices e os indicadores do Índice $\mathrm{P}+\mathrm{L}$, bem como a composição de cada indicador e os percentuais de importância de ambos. 
Quadro 3 - Índice P+L: Sub-índices e Indicadores - composições e percentuais de importância

\begin{tabular}{|c|c|c|c|c|}
\hline \multicolumn{2}{|r|}{ Índice P+L: 05 Sub-índices (SI) e 21 Indicadores } & \multirow{2}{*}{$\begin{array}{l}\text { Composição } \\
\text { do indicador }{ }^{1}\end{array}$} & \multirow{2}{*}{\multicolumn{2}{|c|}{$\begin{array}{c}\text { Importância } \\
\text { de cada ítem } \\
(\%)^{2}\end{array}$}} \\
\hline SI & Indicadores & & & \\
\hline 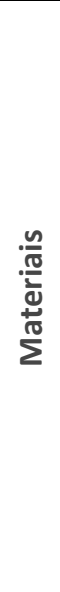 & $\begin{array}{l}\text { IM-1: Consumo de matéria-prima por produto } \\
\text { produzido (t/t); } \\
\text { IM-2: Percentual de matérias-primas renováveis } \\
\text { utilizadas (\%); } \\
\text { IM-3: Percentual de matérias-primas recicladas } \\
\text { utilizadas (\%); } \\
\text { IM-4: Consumo de produtos perigosos por } \\
\text { produto produzido (kg/t); } \\
\text { IM-5: Composição percentual de materiais } \\
\text { recicláveis no produto final (\%); } \\
\text { IM-6: Composição percentual de materiais } \\
\text { perigosos no produto final (\%); }\end{array}$ & $\begin{array}{c}(\mathrm{b} / \mathrm{a}) \\
(\mathrm{c} / \mathrm{b}) \\
(\mathrm{e} / \mathrm{b}) \\
\left(10^{3} . \mathrm{f} / \mathrm{a}\right) \\
\text { Indicador }{ }^{3} \\
\text { desconsiderad } \\
\text { o } \\
\text { Indicador }{ }^{3} \\
\text { desconsiderad } \\
\text { o }\end{array}$ & $\begin{array}{l}4,69 \\
4,64 \\
4,55\end{array}$ & $\begin{array}{l}\text { ดे } \\
\text { बे }\end{array}$ \\
\hline 总 & 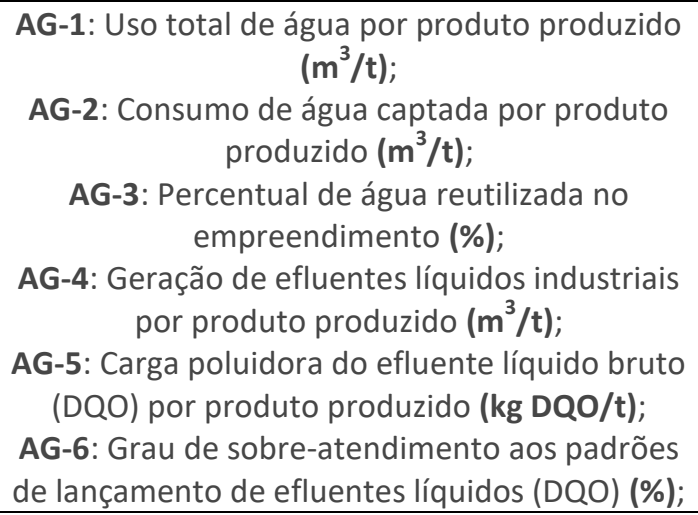 & $\begin{array}{l}\text { (g/a) } \\
(\mathrm{h} / \mathrm{a}) \\
(\mathrm{i} / \mathrm{g}) \\
(\mathrm{j} / \mathrm{a}) \\
(\mathrm{l} / \mathrm{a}) \\
(\mathrm{m})\end{array}$ & $\begin{array}{l}5,09 \\
5,07 \\
4,65 \\
4,95\end{array}$ & बें \\
\hline 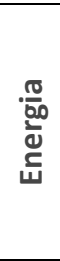 & $\begin{array}{l}\text { EN-1: Consumo total de energia por produto } \\
\text { produzido (kWh/t); } \\
\text { EN-2: Consumo de energia elétrica por produto } \\
\text { produzido (kWh/t); } \\
\text { EN-3: Percentual de energia consumida oriunda } \\
\text { de fontes renováveis }(\%) ;\end{array}$ & $\begin{array}{l}\left(10^{3} . n / a\right) \\
\left(10^{3} . o / a\right) \\
{[q /(n-p)]}\end{array}$ & $\begin{array}{l}4,25 \\
4,94\end{array}$ & 告 \\
\hline 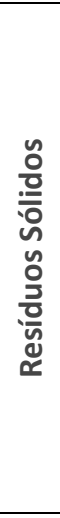 & $\begin{array}{l}\text { RS-1: Geração de resíduos sólidos por produto } \\
\text { produzido (kg/t); } \\
\text { RS-2: Geração de resíduos sólidos perigosos por } \\
\text { produto produzido (kg/t); } \\
\text { RS-3(a): Percentual de resíduos sólidos } \\
\text { aterrados (\%); } \\
\text { RS-3(b): Percentual de resíduos sólidos } \\
\text { incinerados (\%); } \\
\text { RS-3(c): Percentual de resíduos destinados à } \\
\text { valorização energética (\%); } \\
\text { RS-3(d): Percentual de resíduos reutilizados / } \\
\text { reciclados / reaproveitados (\%); }\end{array}$ & $\begin{array}{c}{\left[10^{3} \cdot(\mathrm{r}+\mathrm{s}) / \mathrm{a}\right]} \\
(\mathrm{r} / \mathrm{a}) \\
{[\mathrm{t} /(\mathrm{r}+\mathrm{s})]} \\
{[\mathrm{u} /(\mathrm{r}+\mathrm{s})]} \\
{[\mathrm{v} /(\mathrm{r}+\mathrm{s})]} \\
{[\mathrm{w} /(\mathrm{r}+\mathrm{s})]}\end{array}$ & 4,83 & ڤָ \\
\hline 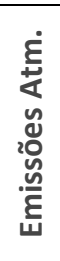 & $\begin{array}{l}\text { EA-1: Emissão de gases causadores de efeito } \\
\text { estufa por produto produzido (kg eqCO2/t); } \\
\text { EA-2: Carga de material particulado (MP) } \\
\text { emitida por produto produzido (kg MP/t); } \\
\text { EA-3: Grau de sobre-atendimento aos padrões } \\
\text { de emissões atmosféricas (\%). }\end{array}$ & $\begin{array}{c}\left(10^{6} \cdot x / a\right) \\
\left(10^{3} \cdot y / a\right) \\
(z)\end{array}$ & $\begin{array}{l}4,80 \\
4,70\end{array}$ & İ \\
\hline
\end{tabular}




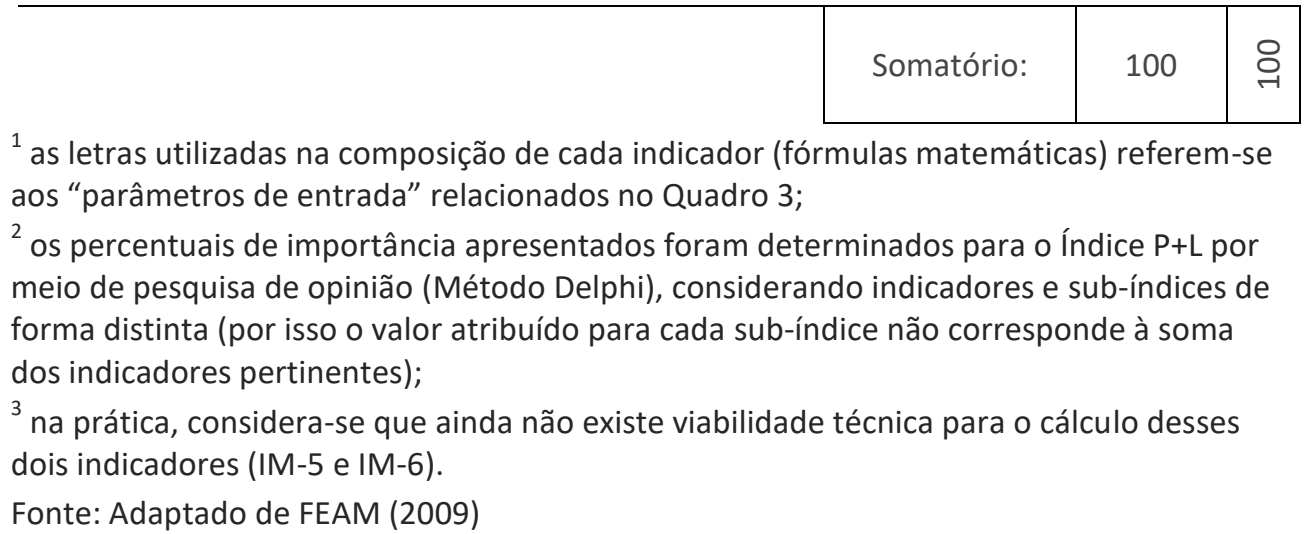

Os dados de entrada solicitados abrangem quantidades dentro do período de um ano (informações referentes ao ano anterior e também ao ano atual), englobando os principais produtos produzidos; as matérias-primas utilizadas; os produtos químicos perigosos utilizados; o consumo de água; a geração de efluentes líquidos; as características dos efluentes líquidos industriais e sanitários; o consumo de energia elétrica; o consumo de energia térmica; os resíduos sólidos; e as emissões atmosféricas (FEAM, 2009). O Quadro 4 apresenta os dados solicitados às empresas e os parâmetros gerados para a composição do Índice $\mathrm{P}+\mathrm{L}$.

Quadro 4 - Índice P+L: dados solicitados às empresas e os parâmetros gerados (informações referentes ao ano anterior e também ao ano atual)

\begin{tabular}{|c|c|c|c|c|}
\hline & $\begin{array}{c}\text { Dados } \\
\text { solicitados } \\
\text { (valores anuais) }\end{array}$ & $\begin{array}{l}\text { Uni- } \\
\text { dade }\end{array}$ & Observações & $\begin{array}{c}\text { Parâmetros de } \\
\text { entrada }^{1}\end{array}$ \\
\hline 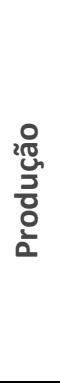 & $\begin{array}{c}\text { Quantidade de } \\
\text { produtos } \\
\text { produzidos }\end{array}$ & $\mathrm{t}$ & $\begin{array}{l}\text { Referente aos (até três) } \\
\text { principais produtos } \\
\text { comercializados pelo } \\
\text { empreendimento; } \\
\text { Informar acerca do } \\
\text { percentual de materiais } \\
\text { recicláveis e compostos } \\
\text { perigosos na composição dos } \\
\text { produtos (se possível) }\end{array}$ & a - Produção anual (t). \\
\hline \multirow{2}{*}{$\begin{array}{l}\frac{n}{\frac{n}{2}} \\
\frac{0}{d} \\
\frac{\pi}{\pi} \\
\sum\end{array}$} & $\begin{array}{l}\text { Quantidade de } \\
\text { matéria-prima }\end{array}$ & $\mathrm{t}$ & $\begin{array}{c}\text { Referente às (até três) } \\
\text { principais matérias-primas } \\
\text { utilizadas no } \\
\text { empreendimento; } \\
\text { Informar, dentre elas, as } \\
\text { quantidades renovável e } \\
\text { reciclada (se houver) }\end{array}$ & \multirow{2}{*}{$\begin{array}{c}\text { b - Consumo de } \\
\text { matérias-primas }(\mathbf{t}) ; \\
\text { c- Consumo de } \\
\text { matéria-prima } \\
\text { renovável }(\mathbf{t}) ; \\
\text { d - Consumo de } \\
\text { matéria-prima não } \\
\text { renovável }{ }^{2}(\mathbf{t}) ; \\
\text { e - Consumo de } \\
\text { matéria-prima } \\
\text { reciclada }(\mathbf{t}) ; \\
\text { f- Consumo de } \\
\text { produtos perigosos }(\mathbf{t}) \text {. }\end{array}$} \\
\hline & $\begin{array}{l}\text { Quantidade de } \\
\text { produtos } \\
\text { químicos } \\
\text { perigosos }\end{array}$ & $\mathrm{t}$ & $\begin{array}{l}\text { Referente aos (até seis) } \\
\text { produtos químicos } \\
\text { considerados perigosos } \\
\text { consumidos em maior } \\
\text { quantidade no } \\
\text { empreendimento }\end{array}$ & \\
\hline
\end{tabular}




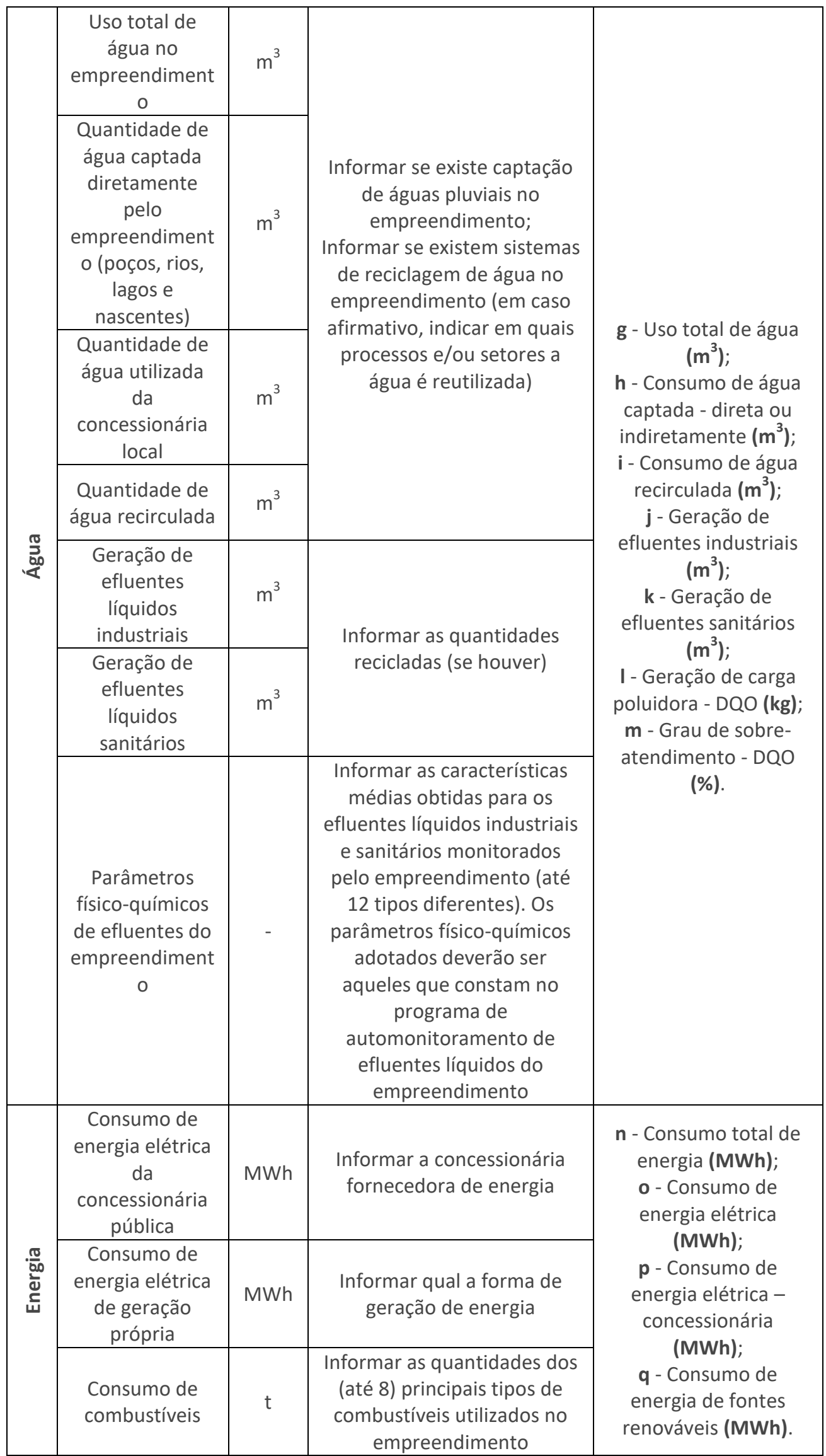




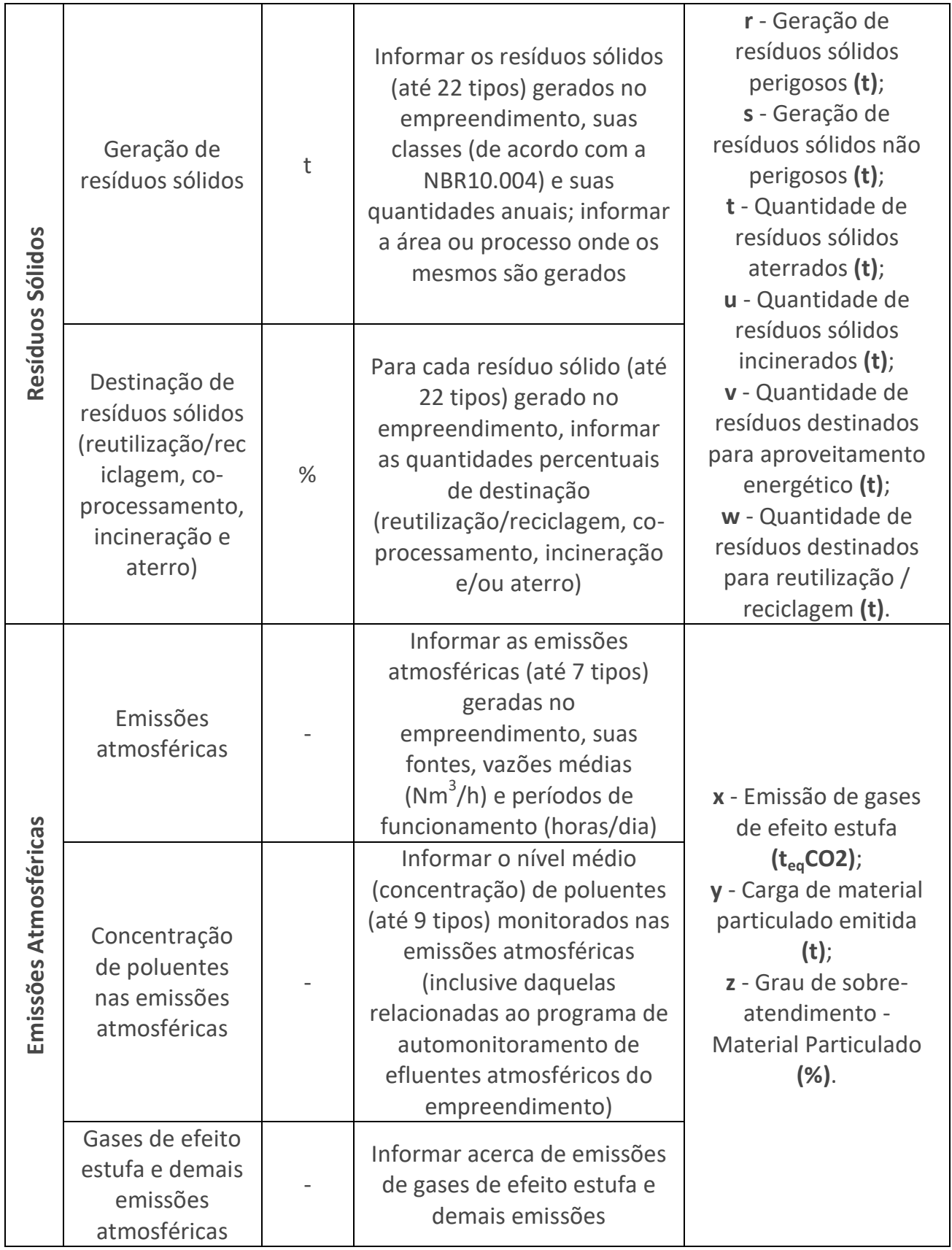

${ }^{1}$ parâmetros (gerados a partir dos dados solicitados às empresas) componentes dos indicadores pertencentes aos sub-índices do Índice $\mathrm{P}+\mathrm{L}$, apresentados no Quadro 3;

${ }^{2}$ dado não utilizado na composição dos indicadores, conforme relação apresentada no Quadro 3.

Fonte: Adaptado de FEAM (2009)

A priorização do Índice $\mathrm{P}+\mathrm{L}$, devido às ponderações aplicadas, varia de acordo com o setor industrial abordado. O Quadro 5 apresenta as priorizações da metodologia, de acordo com o setor industrial e a respectiva ponderação final.

Quadro 5 - Índice P+L: sub-índices prioritários em cada setor industrial 


\begin{tabular}{|c|c|c|c|c|c|c|c|}
\hline $\begin{array}{c}\text { Setores } \\
\text { industriais }\end{array}$ & $\begin{array}{c}\text { Sub- } \\
\text { índices }\end{array}$ & IM & AG & EN & RS & EA & Total \\
\hline \multirow{2}{*}{ Cimento } & $\begin{array}{c}\text { Pond. } \\
\text { Final }\end{array}$ & 0,225 & 0,162 & 0,210 & 0,191 & 0,212 & 1,000 \\
\hline & $\%$ & 22,5 & 16,2 & 21,0 & 19,1 & 21,2 & 100,0 \\
\hline \multirow[t]{2}{*}{ Siderurgia } & $\begin{array}{c}\text { Pond. } \\
\text { Final }\end{array}$ & 0,207 & 0,227 & 0,192 & 0,179 & 0,194 & 1,000 \\
\hline & $\%$ & 20,7 & 22,7 & 19,2 & 17,9 & 19,4 & 100,0 \\
\hline \multirow{2}{*}{ Laticínios } & $\begin{array}{l}\text { Pond. } \\
\text { Final }\end{array}$ & 0,225 & 0,203 & 0,210 & 0,191 & 0,170 & 1,000 \\
\hline & $\%$ & 22,5 & 20,3 & 21,0 & 19,1 & 17,0 & 100,0 \\
\hline \multirow[t]{2}{*}{ Têxtil } & $\begin{array}{l}\text { Pond. } \\
\text { Final }\end{array}$ & 0,200 & 0,220 & 0,185 & 0,208 & 0,187 & 1,000 \\
\hline & $\%$ & 20,0 & 22,0 & 18,5 & 20,8 & 18,7 & 100,0 \\
\hline \multirow[t]{2}{*}{ Couro } & $\begin{array}{l}\text { Pond. } \\
\text { Final }\end{array}$ & 0,200 & 0,220 & 0,185 & 0,208 & 0,187 & 1,000 \\
\hline & $\%$ & 20,0 & 22,0 & 18,5 & 20,8 & 18,7 & 100,0 \\
\hline \multirow{2}{*}{$\begin{array}{l}\text { Metal- } \\
\text { mecânica }\end{array}$} & $\begin{array}{c}\text { Pond. } \\
\text { Final }\end{array}$ & 0,207 & 0,227 & 0,192 & 0,179 & 0,194 & 1,000 \\
\hline & $\%$ & 20,7 & 22,7 & 19,2 & 17,9 & 19,4 & 100,0 \\
\hline
\end{tabular}

Fonte: Adaptado de FEAM (2009)

Portanto, considerando os seis setores abordados, o sub-índice com maior representatividade no Índice $\mathrm{P}+\mathrm{L}$ é o referente à Água (prioritário em 4 dos setores), seguido do sub-índice Materiais (prioritário em 2 dos setores).

Os setores industriais abordados podem ser divididos em duas fases de aplicação do Índice P+L. Fase I (FEAM, 2009): Siderurgia integrada, Cimento, Laticínios, Têxtil, Couro e Metal-mecânico (autopeças); e, de maneira complementar, Fase II (GOMES, 2010): Siderurgia não integrada, Cimento, Laticínios, Abate e Refratários.

Uma dificuldade do método é o próprio levantamento de alguns dados, a exemplo do Consumo total de água, da Geração de efluentes líquidos e resíduos, e do Potencial de reciclabilidade e Compostos perigosos no produto final (GOMES, 2010); estes últimos, culminando na dificuldade de utilização dos indicadores IM-5 e IM-6, salientando a necessidade de um desenvolvimento conceitual, metodológico e analítico que oportunize o uso desses indicadores numa futura etapa de aplicação da metodologia (FEAM, 2009);

Outra dificuldade do método reside na identificação de benchmarks (alguns são adotados e outros calculados por meio de pesquisa bibliográfica), evidenciando a necessidade de desenvolver uma base consistente de benchmarks para os indicadores componentes do cálculo do Índice, englobando cada um dos setores industriais alvo (FEAM, 2009);

A metodologia de cálculo do Índice P+L possibilita sua aplicação a todos os empreendimentos de pequeno, médio ou grande porte dos setores da indústria de transformação dentro do Estado de Minas Gerais, podendo ser estendida para outras regiões, desde que seja feita a classificação dos empreendimentos de 
acordo com a Deliberação Normativa COPAM no 74/2004, bem como a definição de benchmarks específicos para cada um dos indicadores (FEAM, 2009).

Outro ponto a ser frisado é a impossibilidade de benchmarking intersetorial, pois o Índice não foi elaborado com esse propósito, nem testado nesse sentido, não podendo, portanto, ser utilizado para tal finalidade em hipótese alguma; além disso, a metodologia é sensível aos benchmarks e há a necessidade de levantamento contínuo dos mesmos (GOMES, 2010); devendo-se ter cuidado na interpretação dos resultados, sempre considerando os processos e produtos do empreendimento (FEAM, 2009).

Enfim, o Índice $\mathrm{P}+\mathrm{L}$ apresenta como vantagem ser um instrumento de incentivo às melhores práticas de produção (GOMES, 2010), oportunizando análises individualizadas de cada sub-índice, assim podendo embasar as tomadas de decisão no sentido da melhoria das áreas mais deficitárias e, consequentemente, do índice como um todo (FEAM, 2009); o método pode ser estendido a outros segmentos e aplicado pelos mais variados setores da indústria de transformação (FEAM, 2009); e a avaliação criteriosa das informações prestadas torna o processo auditável (GOMES, 2010).

\section{IDRSI}

O IDRSI (Índice de Destinação dos Resíduos Sólidos Industriais) é uma ferramenta que visa, de forma alinhada aos conceitos de $\mathrm{P}+\mathrm{L}$, oportunizar uma auto-avaliação da situação das indústrias no que tange ao gerenciamento de seus resíduos sólidos, com foco na destinação dada aos mesmos, podendo embasar tomadas de decisão dos gestores dessas empresas, por meio de auxílio à avaliação, à prevenção e ao controle da poluição industrial (COELHO et al., 2011).

Faz-se uso de um software, desenvolvido para esse fim, onde são introduzidas (no módulo de utilização pelo usuário), entre outras, informações referentes ao setor industrial (Automotivo, Cimenteiro, Energia, Laticínios, Siderúrgico ou Têxtil) - que acessam os respectivos benchmarks, específicos para cada um dos 20 indicadores desta metodologia, conforme o setor industrial escolhido - e referentes aos componentes de cada indicador (dados de entrada, apresentados no Quadro 7, que vão compor as fórmulas matemáticas de cada indicador, conforme exposto no Quadro 6). Todas as informações são processadas matematicamente pelo software (envolvendo, entre outras, operações tais como normalizações e ponderações dos dados) gerando os valores resultantes para cada um dos sete sub-índices (Minimização, Reaproveitamento/Reutilização, Reciclagem, Co-processamento, Incineração, Disposição final, Estocagem) e apresentando seus respectivos valores de referência (padrões estabelecidos, para comparação com os valores calculados), além de gerar o valor do IDRSI (COELHO, 2011).

Há dois métodos de cálculo para obtenção do IDRSI: o somatório (soma de cada 'indicador normalizado multiplicado pela sua respectiva ponderação') e o produtório (produto de cada indicador normalizado elevado à sua respectiva ponderação') (COELHO, 2011).

O IDRSI corresponde a um número entre 0 e 1 que, por meio de um relatório de análise gerado pelo software, é enquadrado em uma tabela que abrange as seguintes faixas de classificação: muito ruim $(<0,4)$, ruim $(0,4$ a 0,5$)$, tolerável $(0,5$ 
a 0,6$)$, regular $(0,6$ a 0,7$)$, bom $(0,7$ a 0,8$)$, muito bom $(0,8$ a 0,9$)$ e excelente $(0,9$ a $1,0)$, representando uma indicação da situação da empresa no que se refere a destinação dos seus resíduos sólidos industriais. O Índice de Destinação dos Resíduos Sólidos Industriais (IDRSI) é constituído por sete sub-índices que, por sua vez, são compostos por conjuntos de indicadores (COELHO, 2011). A Figura 5 apresenta a disposição esquemática do IDRSI, seus sub-índices, classificação e quantidade dos indicadores.

Figura 5 - Disposição esquemática do IDRSI, seus sub-índices, classificação e quantidade de indicadores

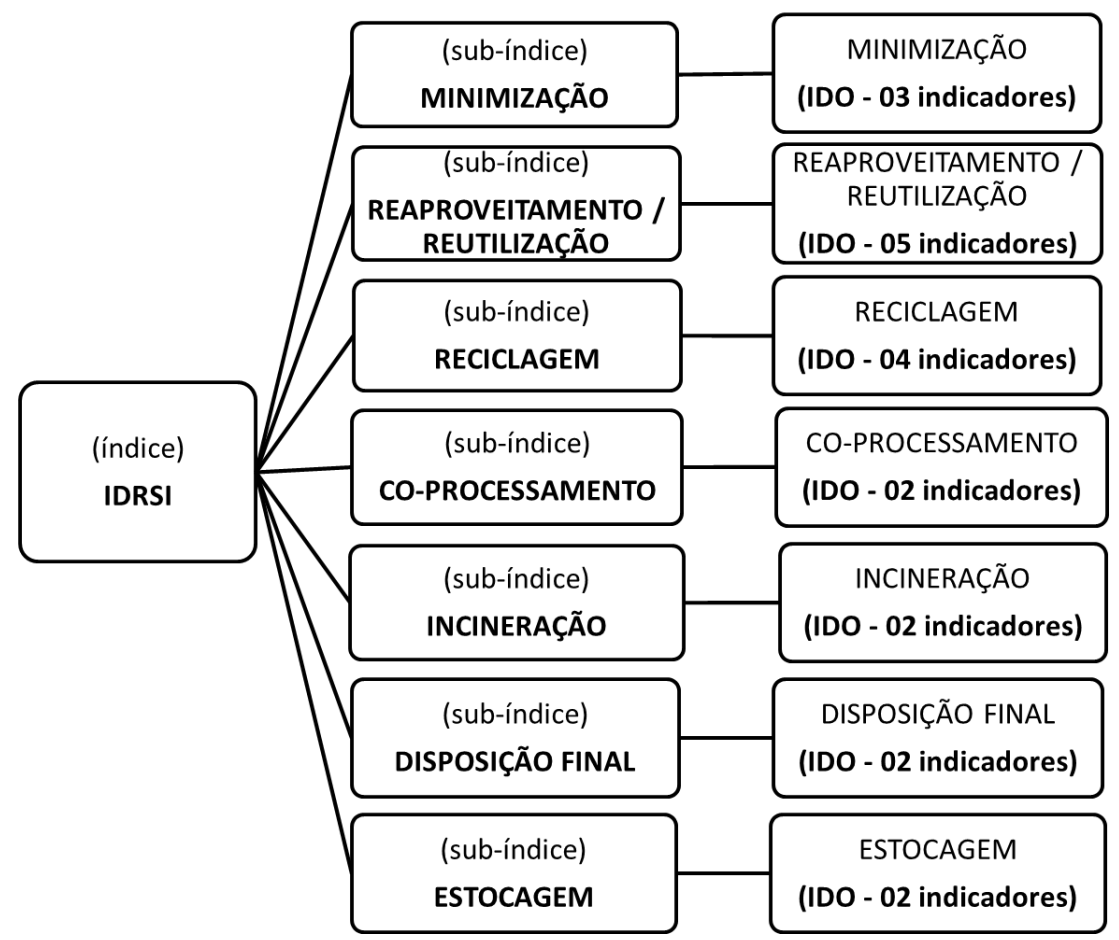

IDO: Indicador de Desempenho Operacional

Fonte: Adaptado de Coelho (2011)

Os indicadores que compõem os sub-índices do IDRSI também podem ser classificados como Indicadores comparativos temporais ou Indicadores percentuais (COELHO, 2011). O Quadro 6 apresenta detalhadamente os subíndices e os indicadores do IDRSI, bem como a composição de cada indicador e os percentuais de importância de ambos.

Quadro 6 - IDRSI: Sub-índices e Indicadores - composições e percentuais de importância

\begin{tabular}{|c|c|c|c|c|}
\hline \multicolumn{2}{|r|}{ IDRSI: 07 Sub-índices (SI) e 20 Indicadores } & \multirow{2}{*}{$\begin{array}{c}* \text { Composição } \\
\text { do indicador }\end{array}$} & \multirow{2}{*}{\multicolumn{2}{|c|}{$\begin{array}{c}\text { Importância } \\
\text { de cada ítem } \\
(\%)\end{array}$}} \\
\hline SI & Indicadores & & & \\
\hline : & $\begin{array}{l}\text { MR-1: Total de resíduos gerados por total de } \\
\text { produtos produzidos (ano atual/ano anterior); } \\
\text { MR-2: Resíduos classe-I gerados por total de } \\
\text { produtos produzidos (ano atual/ano anterior); } \\
\text { MR-4: Resíduos classe-l gerados por total de } \\
\text { resíduos gerados (ano atual/ano anterior); }\end{array}$ & $\begin{array}{l}\text { (b/a) / (b/a) } \\
\text { (c/a) / (c/a) } \\
\text { (c/b) / (c/b) }\end{array}$ & $\begin{array}{l}6,8 \\
6,6 \\
6,2\end{array}$ & ڤُ \\
\hline
\end{tabular}




\begin{tabular}{|c|c|c|c|c|}
\hline 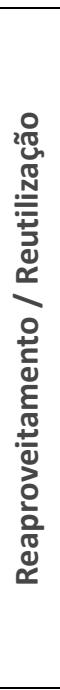 & $\begin{array}{l}\text { RR-1: Percentual total de resíduos reutilizados } \\
\text { ou reaproveitados em relação ao total de } \\
\text { resíduos gerados (no ano atual); } \\
\text { RR-2: Total de resíduos reaproveitados por total } \\
\text { de resíduos gerados (ano atual/ano anterior); } \\
\text { RR-4: Percentual de substituição de combustível } \\
\text { não-renovável na produção decorrente da } \\
\text { reutilização ou reaproveitamento de resíduos } \\
\text { (no ano atual); } \\
\text { RR-5: Percentual de substituição de matéria- } \\
\text { prima decorrente da reutilização ou } \\
\text { reaproveitamento de resíduos (no ano atual); } \\
\text { RR-6: Percentual de resíduo total transferido a } \\
\text { outra indústria para substituição de matéria- } \\
\text { prima ou aproveitamento energético (no ano } \\
\text { atual); }\end{array}$ & $(\mathrm{e} / \mathrm{b}) /(\mathrm{e} / \mathrm{b})$ & 3,3 & $\stackrel{m}{\stackrel{m}{f}}$ \\
\hline 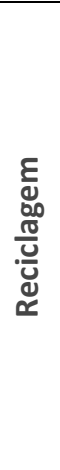 & $\begin{array}{l}\text { RC-1: Percentual total de resíduos reciclados em } \\
\text { relação ao total de resíduos gerados (no ano } \\
\text { atual); } \\
\text { RC-2: Total de resíduos reciclados por total de } \\
\text { resíduos gerados (ano atual/ano anterior); } \\
\text { RC-4: Percentual de substituição de combustível } \\
\text { não-renovável na produção decorrente da } \\
\text { reciclagem de resíduos (no ano atual); } \\
\text { RC-5: Percentual de substituição de matéria- } \\
\text { prima decorrente da reciclagem de resíduos (no } \\
\text { ano atual); }\end{array}$ & $\begin{array}{c}(\mathrm{i} / \mathrm{b}) \\
(\mathrm{i} / \mathrm{b}) /(\mathrm{i} / \mathrm{b}) \\
\text { (j) }\end{array}$ & $\begin{array}{l}4,2 \\
3,9\end{array}$ & $\begin{array}{l}\sigma \\
\text { Gे } \\
\sigma\end{array}$ \\
\hline 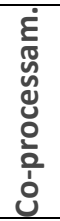 & $\begin{array}{l}\text { CO-3: Total de resíduos co-processados por total } \\
\text { de resíduos gerados (ano atual/ano anterior); } \\
\text { CO-4: Resíduos classe-I co-processados por } \\
\text { resíduos classe-I gerados (ano atual/ano } \\
\text { anterior); }\end{array}$ & $\begin{array}{l}(\mathrm{l} / \mathrm{b}) /(\mathrm{l} / \mathrm{b}) \\
(\mathrm{m} / \mathrm{c}) /(\mathrm{m} / \mathrm{c})\end{array}$ & 5,8 & $\stackrel{\infty}{\rightarrow}$ \\
\hline 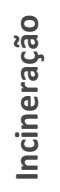 & $\begin{array}{l}\text { IN-3: Total de resíduos incinerados por total de } \\
\text { resíduos gerados (ano atual/ano anterior); } \\
\text { IN-4: Resíduos classe-I incinerados por resíduos } \\
\text { classe-I gerados (ano atual/ano anterior); }\end{array}$ & $\begin{array}{l}(\mathrm{n} / \mathrm{b}) /(\mathrm{n} / \mathrm{b}) \\
(\mathrm{o} / \mathrm{c}) /(\mathrm{o} / \mathrm{c})\end{array}$ & 5,8 & $\hat{F}$ \\
\hline 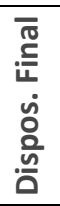 & $\begin{array}{l}\text { DF-3: Total de resíduos aterrados por total de } \\
\text { resíduos gerados (ano atual/ano anterior); } \\
\text { DF-4: Resíduos classe-l aterrados por resíduos } \\
\text { classe-I gerados (ano atual/ano anterior); }\end{array}$ & $\begin{array}{l}(p / b) /(p / b) \\
(q / c) /(q / c)\end{array}$ & 6,1 & $\stackrel{m}{\underset{y}{*}}$ \\
\hline \multirow[t]{2}{*}{ 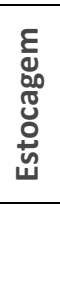 } & $\begin{array}{l}\text { ES-3: Total de resíduos estocados por total de } \\
\text { resíduos gerados (ano atual/ano anterior); } \\
\text { ES-4: Resíduos classe-I estocados por resíduos } \\
\text { classe-I gerados (ano atual/ano anterior). }\end{array}$ & $\begin{array}{l}(\mathrm{r} / \mathrm{b}) /(\mathrm{r} / \mathrm{b}) \\
(\mathrm{s} / \mathrm{c}) /(\mathrm{s} / \mathrm{c})\end{array}$ & $\begin{array}{l}5,2 \\
5,2\end{array}$ & 今े \\
\hline & & Somatório: & 100 & 요 \\
\hline
\end{tabular}

*As letras utilizadas na composição de cada indicador (fórmulas matemáticas) referem-se aos dados de entrada (dados solicitados às empresas) relacionados no Quadro 7

Fonte: Adaptado de Coelho (2011)

Os dados solicitados abrangem quantidades dentro do período de um ano (informações referentes ao ano anterior e também ao ano atual), englobando os dados de entrada necessários para a composição de todos os indicadores 
pertencentes aos sub-índices do IDRSI (COELHO, 2011). O Quadro 7 apresenta os dados solicitados às empresas para a composição do IDRSI.

Quadro 7 - IDRSI: dados solicitados às empresas (informações referentes ao ano anterior e também ao ano atual)

\begin{tabular}{|c|c|c|}
\hline & Dados solicitados (quantidades anuais) & Unidade \\
\hline a & Produção & $\mathrm{t}^{1}$ \\
\hline b & Quantidade total de resíduo sólido gerada & $\mathrm{t}$ \\
\hline c & Quantidade de resíduo sólido perigoso gerada & $\mathrm{t}$ \\
\hline$d^{2}$ & Quantidade de resíduo sólido não-perigoso gerada & $\mathrm{t}$ \\
\hline e & Quantidade total de resíduo sólido reutilizada ou reaproveitada & $\mathrm{t}$ \\
\hline$f$ & $\begin{array}{l}\text { Percentual de combustível não-renovável poupado devido à } \\
\text { reutilização ou reaproveitamento de resíduo sólido }\end{array}$ & $\%$ \\
\hline g & $\begin{array}{c}\text { Percentual de matéria-prima poupada devido à reutilização ou } \\
\text { reaproveitamento de resíduo sólido }\end{array}$ & $\%$ \\
\hline h & $\begin{array}{c}\text { Percentual de resíduo transferido à outra indústria para servir como } \\
\text { matéria-prima ou combustível }\end{array}$ & $\%$ \\
\hline i & Quantidade de resíduo sólido reciclada & $\mathrm{t}$ \\
\hline j & $\begin{array}{l}\text { Percentual de combustível não-renovável poupado devido à } \\
\text { reciclagem de resíduo sólido }\end{array}$ & $\%$ \\
\hline k & $\begin{array}{l}\text { Percentual de matéria-prima poupada devido à reciclagem de } \\
\text { resíduo sólido }\end{array}$ & $\%$ \\
\hline I & Quantidade de resíduo sólido co-processada & $\mathrm{t}$ \\
\hline $\mathrm{m}$ & Quantidade de resíduo sólido perigoso co-processada & $\mathrm{t}$ \\
\hline n & Quantidade de resíduo sólido incinerada & $\mathrm{t}$ \\
\hline 0 & Quantidade de resíduo sólido perigoso incinerada & $\mathrm{t}$ \\
\hline $\mathbf{p}$ & Quantidade de resíduo sólido aterrada & $T$ \\
\hline$q$ & Quantidade de resíduo sólido perigoso aterrada & $\mathrm{t}$ \\
\hline$r$ & Quantidade de resíduo sólido estocada & $\mathrm{t}$ \\
\hline$S$ & Quantidade de resíduo sólido perigoso estocada & $\mathrm{t}$ \\
\hline
\end{tabular}

${ }^{1}$ para o Setor Energético (energia elétrica) a unidade de produção deve ser medida em kWh;

${ }^{2}$ dado não utilizado na composição dos indicadores, conforme relação apresentada no Quadro 6.

Fonte: Adaptado de Coelho (2011)

A P+L se caracteriza por ações que privilegiem o Nível 1 (redução na fonte) como prioritárias, seguidas do Nível 2 (reciclagem interna) e Nível 3 (reciclagem externa), nesta ordem (CNTL, 2003a).

Em análise aos percentuais de importância dos componentes do IDRSI (vide Quadro 6), o Nível 1 da $\mathrm{P}+\mathrm{L}$ corresponde ao sub-índice Minimização (que tem $19,6 \%$ de importância) e os Níveis 2 e 3 da P+L englobam os sub-índices Reaproveitamento/Reutilização e Reciclagem (que somados tem $34,2 \%$ de importância).

Dessa forma, verifica-se que a priorização do IDRSI é direcionada à destinação dos resíduos que não puderam ser evitados por meio das ações 
envolvendo os Níveis 1,2 e 3 da $P+L$, englobando, portanto, a soma dos percentuais de importância de quatro sub-índices (co-processamento, incineração, destinação final e estocagem), apresentando-se com a maior representatividade desta metodologia: $46,2 \%$ de importância.

Foram escolhidos seis setores industriais para a aplicação do IDRSI: Automotivo, Cimenteiro, Energético (energia elétrica), Laticínios, Siderúrgico e Têxtil (COELHO, 2011).

O método apresenta discrepância entre os resultados do IDRSI somatório e produtório: o produtório é um método mais sensível à existência de valores extremos (mínimo e máximo) nos sub-índices (COELHO et al., 2011), já o somatório é mais sensível à quantidade de dados fornecidos pelas empresas analisadas, sendo recomendado para a composição do IDRSI (COELHO, 2011), principalmente quando se deseja "conhecer o rendimento geral da empresa em todos os quesitos analisados" (COELHO et al., 2011, p.312).

O método apresenta como dificuldade a obtenção de dados para o estabelecimento dos benchmarks, prejudicando assim a consolidação de valores de referência mais realistas para os indicadores do IDRSI; bem como distorções devido ao tratamento de dados inexistentes: nos casos em que os dados reais não estão disponíveis, adota-se como critério a utilização de valores nulos (COELHO et al., 2011), dessa forma, algumas empresas são privilegiadas quando não apresentam dados para o cálculo de determinados indicadores, gerando valores máximos, mesmo que o desempenho tenha sido mínimo e não fornecido (COELHO, 2011); no método IDRSI produtório os valores dos indicadores iguais a zero são desconsiderados (COELHO et al., 2011); ademais, "quando dados fornecidos ultrapassam os intervalos balizados pelos benchmarks, o valor do indicador foge da escala, adquirindo proporções indevidas", podendo gerar resultados errôneos e interpretações precipitadas (COELHO, 2011, p.208).

Considerando o tripé da sustentabilidade, o IDRSI restringe-se a questões ambientais, não contemplando aspectos econômicos e sociais; dentro desse mote, o IDRSI "é voltado estritamente para os setores industriais, buscando avaliar os resíduos sólidos gerados em indústrias, sendo eles classificados conforme NBR-10.004/2004" (COELHO, 2011, p.71); os indicadores foram desenvolvidos para seis setores industriais específicos (automotivo, cimenteiro, energético - energia elétrica, laticínios, siderúrgico e têxtil), não sendo aplicáveis, portanto, à indústria extrativa (COELHO, 2011).

Os dados obtidos, via cálculo, para o estabelecimento de benchmarks para os indicadores do IDRSI são provenientes, em sua maioria, de grandes empresas (muitas vezes multinacionais), evidenciando a precariedade de informações referentes às micro e pequenas indústrias no Brasil. Cabe salientar também, que os benchmarks são valores dinâmicos, devendo ser atualizados periodicamente (COELHO, 2011), acarretando, consequentemente, na necessidade contínua da atualização do software do IDRSI.

O IDRSI pode ser aplicado em indústrias de qualquer porte; foi desenvolvido para seis setores industriais específicos, mas pode ser ampliado para outros setores; permitindo às indústrias a avaliação da sua situação interna quanto ao gerenciamento de resíduos sólidos, possibilitando aos seus gestores "tomarem as decisões de forma adequada e em tempo hábil, evitando impactos ambientais, 
reduzindo custos e agindo na prevenção e controle da poluição industrial" (COELHO, 2011, p.81).

\section{METODOLOGIA}

A pesquisa possui natureza qualitativa no tocante aos temas tratados; quanto aos objetivos, classifica-se como exploratória e no que concerne aos seus procedimentos técnicos, como bibliográfica. Foram utilizadas referências compreendendo teses, livros técnicos, normas e leis, além de artigos de eventos e periódicos (GIL, 2002; MENEZES e SILVA, 2005; LAKATOS e MARCONI, 2006).

\section{ANÁLISES E DISCUSSÕES}

As análises e discussões são pautadas em nove sub-tópicos, na seguinte ordem sequencial: Descrição da metodologia; Abordagem e percentuais de importância dos aspectos ambientais (ou sub-índices) e indicadores; Dados solicitados às empresas; Prioridade do sistema (ou índice); Setores industriais abordados; Dificuldades; Aplicabilidade, restrições e limitações; Vantagens e Contribuições das três metodologias (SAPmaisL, Índice P+L, IDRSI) à Política Nacional de Resíduos Sólidos.

\section{ANÁLISE DAS DESCRIÇÕES DAS METODOLOGIAS}

As três metodologias abordadas tem como pontos comuns a Avaliação de Desempenho Ambiental e o alinhamento com os conceitos de Produção mais Limpa, e foram concebidas para aplicações com diferentes focos.

O SAPmaisL tem seu foco na implementação de opções de $P+L$ e acompanhamento dos resultados por meio do monitoramento de indicadores 'pós-definidos' (definidos conforme as demandas de cada empresa), que devem compor, a princípio, três dos 11 aspectos ambientais pré-selecionados (Consumo: de matéria-prima; de insumos significativos; de água; de energia elétrica; e de combustíveis. Geração: de resíduos sólidos classe I; classe II; de efluente líquido; de carga orgânica no efluente líquido; de carga inorgânica no efluente líquido; e de emissões atmosféricas), visando a melhoria contínua, compreendendo considerações ambientais e econômicas.

O Índice $\mathrm{P}+\mathrm{L}$ tem seu foco no monitoramento de 21 indicadores 'prédefinidos', que compõem cinco campos apontados como significativos para empreendimentos da indústria de transformação (Materiais, Água, Energia, Resíduos Sólidos e Emissões Atmosféricas), compreendendo considerações ambientais, e gerando um índice que representa essa gestão.

O IDRSI tem seu foco no monitoramento de 20 indicadores 'pré-definidos', que compõem sete quesitos envolvendo o gerenciamento de resíduos sólidos, com ênfase na destinação dos mesmos (Minimização, Reaproveitamento/Reutilização, Reciclagem, Co-processamento, Incineração, Disposição final e Estocagem), compreendendo considerações ambientais, e gerando um índice que representa essa gestão. 
O SAPmaisL dispõe de 11 aspectos ambientais pré-selecionados, que agregam seus respectivos indicadores de desempenho operacional (IDO). Os indicadores não são pré-definidos e os aspectos ambientais não se configuram como sub-índices, pois não há interação entre os mesmos no sentido de constituir um único índice.

Dessa forma, os indicadores do SAPmaisL não apresentam percentuais de importância pré-definidos (pois são eleitos de acordo com as demandas das empresas) e tem sua composição inspirada pelos indicadores de $\mathrm{P}+\mathrm{L}$, conforme exemplificado no Quadro 1.

A abordagem dos aspectos ambientais do SAPmaisL se assemelha muito à do Índice $P+L$, pois também está inserida nos campos Materiais, Água, Energia, Resíduos Sólidos e Emissões Atmosféricas (salientando que, no Índice $\mathrm{P}+\mathrm{L}$, o aspecto Efluentes Líquidos se encontra implícito no campo Água).

O Índice $\mathrm{P}+\mathrm{L}$, conforme apresentado no Quadro 3, dispõe de cinco campos (ou sub-índices), sendo compostos por indicadores de desempenho operacional (IDO) condizentes com a seguinte distribuição: Materiais, Água, Energia, Resíduos Sólidos e Emissões Atmosféricas.

Em análise aos 21 indicadores que compõem o Índice $\mathrm{P}+\mathrm{L}$ :

- Nove deles (IM-2-3-5-6, AG-3-6, EN-3, RS-3 e EA-3) são indicadores percentuais; e 12 deles (IM-1-4, AG-1-2-4-5, EN-1-2, RS-1-2 e EA-1-2) são, de acordo com FEAM (2009, p.27), indicadores de ecoeficiência (pois relacionam "um aspecto ou grandeza ambiental com uma grandeza econômica, no caso o nível de produção do empreendimento").

Quanto aos percentuais de importância dos indicadores e sub-índices na composição final do Índice $\mathrm{P}+\mathrm{L}$ : o percentual de importância de cada indicador pode variar em função do número total de indicadores utilizados e da ponderação referente a cada setor industrial.

O IDRSI, conforme apresentado na Figura 3, dispõe de sete quesitos (ou subíndices) abrangendo a gestão de resíduos sólidos, sendo compostos por indicadores de desempenho operacional (IDO) condizentes com a seguinte distribuição: Minimização, Reaproveitamento/Reutilização, Reciclagem, Coprocessamento, Incineração, Disposição Final e Estocagem.

Em análise aos 20 indicadores que compõem o IDRSI:

- Sete deles (RR-1-4-5-6, RC-1-4-5) são indicadores percentuais; e 13 deles (MR-1-2-4, RR-2, RC-2, CO-3-4, IN-3-4, DF-3-4, ES-3-4) são indicadores comparativos temporais.

Quanto aos percentuais de importância dos indicadores e sub-índices na composição final do IDRSI: o percentual de importância de cada sub-índice corresponde à soma dos percentuais de importância dos seus indicadores correspondentes (conforme apresenta o Quadro 6). 


\section{ANÁLISE DOS DADOS SOLICITADOS ÀS EMPRESAS}

$\mathrm{Na}$ metodologia SAPmaisL, os dados solicitados às empresas (e/ou levantados junto às empresas), a princípio, são os que se referem à realização do diagnóstico ambiental da empresa, demandando atenção aos detalhes que envolvem os processos e também a aplicação de procedimentos confiáveis para a mensuração dos dados de entrada.

$\mathrm{Na}$ metodologia Índice $\mathrm{P}+\mathrm{L}$, os dados solicitados às empresas (conforme apresenta o Quadro 4), são de fácil compreensão, pois possuem observações explicativas para a obtenção das mesmas. Cabe ressaltar que, em algumas solicitações, há um limite para o número de ítens pertinentes a serem informados, o que, a princípio, implica na geração de um índice que considera apenas os dados mais representativos, e não a totalidade dos dados passíveis de serem fornecidos pelos empreendimentos.

Além disso, a metodologia Índice $P+L$ não faz menção aos procedimentos mais confiáveis a serem utilizados para a mensuração desses dados de entrada.

$\mathrm{Na}$ metodologia IDRSI, os dados solicitados às empresas (conforme apresenta o Quadro 7), também são de fácil entendimento, porém, cabe ressaltar que os indicadores RR-4-5-6 e RC-4-5 devem ser fornecidos pelas empresas já em sua forma final (\%).

Além disso, a metodologia IDRSI também não faz menção aos procedimentos mais confiáveis a serem utilizados para a mensuração dos seus dados de entrada.

\section{ANÁLISE DAS PRIORIDADES DOS SISTEMAS (OU ÍNDICES)}

No sistema SAPmaisL não há definição prévia de priorização entre os aspectos ambientais abordados; no Índice $\mathrm{P}+\mathrm{L}$, a priorização varia de acordo com os setores industriais considerados, sendo que, dentre eles, a maior representatividade é referente à Água (sub-índice prioritário em quatro dos seis setores industriais abordados pela metodologia); e o IDRSI prioriza a destinação de resíduos não contemplada pelos Níveis 1,2 e 3 da $P+L$, com representatividade de $46,2 \%$ (englobando os sub-índices co-processamento, incineração, destinação final e estocagem).

\section{ANÁLISE DOS SETORES INDUSTRIAIS ABORDADOS}

As metodologias índice $\mathrm{P}+\mathrm{L}$ e IDRSI abordam cinco setores industriais simultaneamente (Automotivo, Cimenteiro, Laticínios, Siderúrgico e Têxtil), provavelmente por se constituírem como setores proeminentes no estado de Minas Gerais (que é a região objeto de aplicação do Índice $P+L$, constituindo-se também como região de mais fácil acesso quando da confecção do IDRSI).

Ambas as metodologias (Índice P+L e IDRSI) podem ter os seus respectivos setores de aplicação ampliados (requerendo, para isso, pesquisas envolvendo os setores desejados).

Nesse sentido, o SAPmaisL se apresenta como uma ferramenta que, devido à sua própria concepção, torna-se muito mais versátil, motivo pelo qual não foi comparada às outras duas metodologias. 


\section{ANÁLISE DAS DIFICULDADES}

A dificuldade mais recorrente, apontada nas três metodologias, diz respeito à confiabilidade dos dados utilizados (necessidade de aplicação de procedimentos de medição confiáveis e reprodutíveis, entre outros requisitos desejáveis).

Em segundo lugar, envolvendo simultaneamente o Índice $\mathrm{P}+\mathrm{L}$ e o IDRSI, a dificuldade apontada diz respeito à obtenção de dados para o cálculo dos benchmarks (dificultando a consolidação de indicadores de forma mais condizente com a realidade).

No restante, as dificuldades apontadas abarcam questões específicas de cada metodologia: dificuldade de levantamento de alguns dados, no Índice P+L; e discrepâncias e distorções geradas em algumas situações específicas, no IDRSI.

\section{ANÁLISE DAS APLICABILIDADES, RESTRIÇÕES E LIMITAÇÕES}

A aplicabilidade de cada metodologia remete aos setores industriais abordados (e passíveis de abordagem), cabendo relacioná-los também aos portes das empresas, contemplando: no SAPmaisL, a princípio, empresas de qualquer porte; no Índice $\mathrm{P}+\mathrm{L}$, empreendimentos de pequeno, médio ou grande portes (provavelmente devido à utilização da DN COPAM no 74/2004, que aborda esses três portes de empresas); e no IDRSI, indústrias de qualquer porte (apesar de os dados obtidos para o estabelecimento dos benchmarks, em sua maioria, serem provenientes de grandes empresas).

Quanto às restrições, o SAPmaisL exige que as empresas já tenham aplicado alguma ação em $\mathrm{P}+\mathrm{L}$, pertençam a um dos setores produtivos contemplados pelo projeto, e não tenham pendências junto ao órgão ambiental responsável; o Índice P+L enfatiza que deve ser utilizada a DN COPAM no 74/2004 para a classificação dos empreendimentos, mesmo que a empresa esteja localizada fora do estado de Minas Gerais; e o IDRSI salienta que não é aplicável à indústria extrativa, devido a metodologia ser voltada, a princípio, estritamente para os seis setores industriais selecionados e seus resíduos, classificados conforme NBR10.004/2004, não contemplando aspectos econômicos e sociais (restringindo-se, portanto, aos aspectos ambientais);

Abarcando um pouco além do que é apresentado neste ítem específico, no que tanje as restrições, o Índice P+L e o IDRSI tem como ponto comum a abordagem estritamente ambiental, diferentemente do SAPmaisL, que também envolve questões econômicas.

Como limitação, o SAPmaisL exige, inicialmente, a escolha de apenas três aspectos ambientais (dentre os 11 abordados na metodologia), devendo haver, no mínimo, um indicador para cada aspecto escolhido (essa determinação, inicialmente limitadora, pode ser otimizada com o passar do tempo, pois, a cada ciclo de melhoria esses números podem ser gradativamente ampliados, aumentando assim o controle sobre os processos e/ou aprimorando os resultados obtidos); o Índice $\mathrm{P}+\mathrm{L}$, por sua vez, ressalta a impossibilidade da realização de benchmarking intersetorial, a sensibilidade da metodologia aos benchmarks e a necessidade de levantamento contínuo dos mesmos, além do cuidado na interpretação dos resultados (devendo sempre ser considerados os 
processos e produtos do empreendimento); já no IDRSI, entende-se como limitação: a utilização de apenas três alternativas de tratamento de resíduos (incineração, co-processamento e aterramento) e questões referentes aos benchmarks (qualidade dos dados utilizados; tendência a contemplarem empresas de grande porte, em detrimento das micro e pequenas; e a característica dinâmica dos mesmos, acarretando na necessidade de atualização periódica e, consequentemente, na necessidade contínua da atualização do software do IDRSI).

Verifica-se, portanto, como item mais recorrente no quesito limitação, questões envolvendo a determinação e a manutenção dos benchmarks, no Índice $\mathrm{P}+\mathrm{L}$ e no IDRSI.

\section{ANÁLISE DAS VANTAGENS}

Quanto as vantagens, o SAPmaisL tem a seu favor as considerações econômicas vinculadas aos indicadores abordados (sendo esse um dos quesitos avaliados para a determinação dos indicadores prioritários a serem utilizados), além do controle mais eficaz e constante dos processos produtivos, motivado pela cobrança por resultados e pelo rigor da avaliação nas auditorias para fornecimento do Certificado de Desempenho Ambiental; já o Índice $\mathrm{P}+\mathrm{L}$ aponta como vantagem a abordagem compreendendo os aspectos ambientais mais significativos aos empreendimentos alvo, bem como da utilização de indicadores usualmente empregados em avaliações de $\mathrm{P}+\mathrm{L}$ nas empresas, atuando como incentivador às melhores práticas de produção e podendo embasar tomadas de decisão direcionadas à melhoria do desempenho ambiental, além de possibilitar seu emprego em outros segmentos e setores da indústria de transformação, por meio de um processo que pode ser auditável; o IDRSI apresenta como vantagem a possibilidade de sua aplicação em indústrias de qualquer porte, permitindo também a ampliação dos setores de aplicação da metodologia e o embasamento para tomadas de decisão, além de possuir um software de operação simplificada.

Dessa forma, as vantagens mais recorrentes apresentadas apontam para o incentivo às práticas de $\mathrm{P}+\mathrm{L}$ e o apoio à tomada de decisão pelos gestores, no sentido a melhoria do desempenho ambiental das operações dos empreendimentos; além disso, considerando especificamente o Índice P+L e o IDRSI, é apontada a possibilidade de ampliação dos setores originalmente abordados por essas metodologias.

\section{CONTRIBUIÇÃO À POLÍTICA NACIONAL DE RESÍDUOS SÓLIDOS}

De maneira geral, no que tange às organizações industriais, as três metodologias apresentadas contribuem com a Política Nacional de Resíduos Sólidos (PNRS) no sentido do atendimento às diretrizes preconizadas pela Lei, devido ao alinhamento dessas ferramentas com os conceitos de $\mathrm{P}+\mathrm{L}$.

Porém, de maneira mais focada no Artigo 9o da PNRS, em cujo texto há a determinação de que "na gestão e gerenciamento de resíduos sólidos, deve ser observada a seguinte ordem de prioridade: não geração, redução, reutilização, reciclagem, tratamento dos resíduos sólidos e disposição final ambientalmente adequada dos rejeitos" (BRASIL, 2012), cabe uma análise envolvendo a P+L e 
também algumas considerações adicionais acerca da contribuição das metodologias apresentadas nesta pesquisa quanto a esta questão.

A fim de ampliar as estratégias de prevenção à poluição envolvidas pela $P+L$ que abarca três níveis hierárquicos de atuação (redução na fonte, reciclagem interna e externa) - tendo como propósito atender de forma mais abrangente ao referido artigo da PNRS, deve-se considerar, complementarmente, abordagens compreendendo desde o tratamento dos resíduos inevitáveis até a disposição final ambientalmente adequada dos rejeitos.

Nesse sentido, o nível 1 da $P+L$ engloba as determinações de "não geração" e "redução"; e os níveis 2 e 3 da P+L as de "reutilização" e "reciclagem"; restando, de forma completiva, as determinações de "tratamento dos resíduos sólidos" (tratamento dos resíduos que não puderam ser evitados por meio de atitudes envolvendo os níveis 1 , 2 e 3 da $\mathrm{P}+\mathrm{L}$ ) e "disposição final ambientalmente adequada dos rejeitos".

Dessa forma, considerando que as priorizações determinadas pelo Artigo 9o da PNRS demandem valores de ponderação (ou valores de importância) decrescentes para cada item (ou seja, valores maiores de ponderação para "não geração" e menores para "disposição final ambientalmente adequada dos rejeitos"), em análise às metodologias abordadas nesta pesquisa:

- O SAPmaisL não prevê priorizações entre os aspectos ambientais considerados; também não apresenta, de forma prévia, uma ordem de priorização a ser obedecida para a determinação de seus indicadores (a priorização dos indicadores depende de análises envolvendo o custo-benefício para as empresas, não implicando, necessariamente, numa orientação alinhada ao Artigo 9o da PNRS, que traz uma abordagem mandatória estritamente ambiental); assim, de forma a contemplar o referido artigo da PNRS, sugere-se que seja introduzida à metodologia uma sistemática que venha a suprir essa demanda;

- O Índice P+L é composto por cinco sub-índices e, entre eles, figura um referente aos Resíduos Sólidos Industriais; ocorre que as melhorias alcançadas nos demais sub-índices podem trazer reflexos positivos a este (advindos acentuadamente do sub-índice referente a Materiais). Trazendo o foco para a análise proposta neste tópico, esta metodologia também não faz menção às considerações preconizadas pelo Artigo 9o da PNRS no cálculo de seus subíndices e/ou indicadores, implicando, portanto, (a título de sugestão) na necessidade de estudos visando a possibilidade da inserção dessa abordagem no Índice $\mathrm{P}+\mathrm{L}$;

- O IDRSI é a única metodologia, dentre as três abordadas nesta pesquisa, totalmente voltada aos Resíduos Sólidos Industriais; e que demonstra um certo alinhamento com o Artigo 9o da PNRS, por abordar sub-índices com conteúdo equivalente ou próximo dos preconizados pelo referido artigo da PNRS, mas sem obedecer totalmente a ordem de prioridade estabelecida. O Quadro 8 apresenta uma comparação entre a priorização estabelecida pela PNRS e a priorização aplicada no IDRSI. 
Quadro 8 - Priorização da gestão de resíduos: PNRS e IDRSI

\begin{tabular}{|c|c|c|c|c|c|}
\hline \multicolumn{2}{|c|}{ Artigo 9 da PNRS } & \multicolumn{4}{|c|}{ IDRSI* } \\
\hline $\begin{array}{l}\text { Prio- } \\
\text { rização }\end{array}$ & Itens & Itens (sub-índices) & \multicolumn{2}{|c|}{$\begin{array}{c}\text { Importância de cada } \\
\text { item }\end{array}$} & $\begin{array}{l}\text { Prio- } \\
\text { rização }\end{array}$ \\
\hline 10 & Não geração & \multirow{2}{*}{ Minimização } & \multirow{2}{*}{\multicolumn{2}{|c|}{$19,6 \%$}} & \multirow{2}{*}{$30 / 40$} \\
\hline 20 & Redução & & & & \\
\hline 3음 & Reutilização & $\begin{array}{c}\text { Reaproveitamento/ } \\
\text { Reutilização }\end{array}$ & \multicolumn{2}{|c|}{$17,3 \%$} & 50 \\
\hline 40 & Reciclagem & Reciclagem & \multicolumn{2}{|c|}{$16,9 \%$} & 60 \\
\hline \multirow[t]{2}{*}{ 50 } & \multirow{2}{*}{$\begin{array}{l}\text { Tratamento dos } \\
\text { resíduos sólidos }\end{array}$} & Co-processamento & $11,8 \%$ & \multirow{2}{*}{$23,5 \%$} & \multirow{2}{*}{10} \\
\hline & & Incineração & $11,7 \%$ & & \\
\hline \multirow[t]{2}{*}{60} & \multirow{2}{*}{$\begin{array}{c}\text { Disposição final } \\
\text { ambientalmente } \\
\text { adequada dos } \\
\text { rejeitos }\end{array}$} & Disposição final & $12,3 \%$ & \multirow[t]{2}{*}{$22,7 \%$} & \multirow[t]{2}{*}{20} \\
\hline & & Estocagem (?) & $10,4 \%$ & & \\
\hline
\end{tabular}

* Os itens (sub-índices) do IDRSI foram organizados de acordo com a afinidade aos seis itens preconizados pela PNRS.

Fonte: Adaptado de Brasil (2012) e Coelho (2011)

A análise das três ferramentas quanto a esse quesito da PNRS, portanto, dá margem para a proposta de reformulação das ponderações (ou da importância) atribuída para cada item, de forma a haver maior valorização das melhorias de acordo com a priorização estabelecida (por exemplo: é inquestionável que uma melhoria no tratamento de resíduos é necessária e muito importante mas, mais importante do que isso, seria uma melhoria no quesito não geração pois, dessa forma, não haveriam resíduos para serem tratados).

Nessa linha de pensamento, esta pesquisa também dá subsídios à confecção de novas metodologias que, além de utilizar ponderações de forma alinhada às priorizações preconizadas pela PNRS, procure minimizar as dificuldades, restrições e limitações observadas nas três ferramentas apresentadas, buscando potencializar suas vantagens e possibilidades de aplicação.

\section{CONSIDERAÇÕES FINAIS}

Ao apresentar e analisar o SAPmaisL, o Índice P+L e o IDRSI de maneira sistemática utilizando questionamentos na forma de tópicos, a pesquisa oportunizou compreensões das metodologias por meio de detalhamento dos seus itens integrantes e pela comparação entre eles. Contemplam-se pontos relevantes no sentido de melhor caracterizá-los, proporcionando, com isso, discernimento entre os objetivos, as abrangências e possibilidades de cada uma delas.

$\mathrm{Na}$ análise, a concepção das três metodologias, mesmo que de forma sucinta, permitiu entender que o SAPmaisL se direciona à obtenção de melhorias pontuais, determinadas de forma a suprir as maiores demandas de cada empresa. O Índice P+L e o IDRSI, por outro lado, buscam apontar oportunidades de melhoria balizadas pelos benchmarks envolvendo seus indicadores e subíndices pré-definidos. Avaliam a gestão ambiental das operações industriais por 
meio de um único índice, que considera, no Índice $\mathrm{P}+\mathrm{L}$, a gestão medida pela interação entre cinco campos apontados como significativos e, no IDRSI, a gestão medida pelos resíduos sólidos industriais, abarcando a interação de sete quesitos já relacionados.

Não se pode afirmar que haja uma hierarquia entre elas, ou qual delas apresentaria melhores resultados, uma vez que para isto seria necessário a análise de contextos e de casos. A priori, nada impede que sejam utilizadas em conjunto, podendo ser complementares quando se busca a excelência do desempenho ambiental. Pressupõe-se que, quanto mais indicadores forem monitorados, maior deverá ser o controle sobre os processos produtivos.

Nesse sentido, o SAPmaisL tem enraizado na sua concepção os procedimentos - calibração dos equipamentos e instrumentos, aplicação de padrões confiáveis e rastreáveis, limites de detecção dos métodos de medição para a implementação e controle da $\mathrm{P}+\mathrm{L}$, além da cobrança por resultados e pelo rigor das auditorias quando do fornecimento do Certificado de Desempenho Ambiental. A metodologia enfatiza a confiabilidade dos resultados apresentados, suprindo, com isso, uma grande necessidade apontada pelo Índice $\mathrm{P}+\mathrm{L}$ e pelo IDRSI, tornando o SAPmaisL uma ferramenta sinérgica à maior confiabilidade dos resultados apresentados por esses índices.

Como as metodologias foram concebidas na essência da Produção mais Limpa, aspecto fundamental para a implementação da Política Nacional de Resíduos Sólidos, pode-se aludir que a sua aplicação fomenta o desenvolvimento sustentável da indústria no país, incentiva as práticas de Produção mais Limpa e a criação de novos Modelos de Avaliação Ambiental para a mais correta gestão de resíduos. 


\title{
Environmental performance evaluation based on cleaner production concepts: an analysis of three methodological proposals (SAPmaisL, P+L Index and IDRSI)
}

\begin{abstract}
Three methodological proposals for Environmental Performance Evaluation are analyzed in this paper: SAPmaisL (Environmental Performance Evaluation System based on Cleaner Production concepts), the $\mathrm{P}+\mathrm{L}$ Index (Cleaner Production Index for the transformation industry in Minas Gerais state) and IDRSI (Index for Industrial Solid Waste Disposal). These methodologies are contextualized to deal with the challenges in industrial organizations scenario in order to comply with legal determinations involving productive processes and the environment. Premises of the National Policy on Solid Waste and Cleaner Production are emphasized as well, as they are tools to support the management of industrial waste alligned with the provisions of the reffered legislation. The target of such research was to enhance the understanding of these methodologies based on discussions, underpinning a critical sense to managers, researchers and the like, and giving subsidies to the choice/elaboration of mechanisms for the waste management in industrial corporations from the perspective of ecoefficiency, thus contributing for the environmental improvement and promoting sustainable development. In conclusion, despite their differences, the researched methodologies are complementary and flexible, allowing companies to obtain support for decision-making related to the conduction of their production processes based on Cleaner Production concepts.
\end{abstract}

KEYWORDS: Cleaner Production. Environmental Performance Evaluation. Indicators. Industrial Solid Waste. National Policy on Solid Waste. 


\section{REFERÊNCIAS}

ABNT. Associação Brasileira de Normas Técnicas. NBR ISO 14031: Gestão ambiental - Avaliação de desempenho ambiental - Diretrizes. Rio de Janeiro: ABNT, 44p., 2004.

ALMEIDA, F. O Bom Negócio da Sustentabilidade. 1.ed. Rio de Janeiro: Nova Fronteira, 2002.

BERTÉLI, M. O.; BARCELLOS, P. F. P.; BORELLA, M. R. C. Mudança organizacional impulsionada pela Produção mais Limpa. Revista Gestão Industrial, v.9, n.4, 2013. crossref

BERTÉLI, M. O.; PESSIN, N. Implantação de técnicas da metodologia de Produção mais Limpa, na produção de embalagens de madeira, em uma empresa do setor metal mecânico. In: Encontro Nacional de Engenharia de Produção, 29., 2009, Salvador. Anais eletrônicos... Rio de Janeiro: ABEPRO, 2009.

BRASIL. Política Nacional de resíduos sólidos. 2aed. Brasília: Câmara dos Deputados, Edições Câmara, 2012. 73p. (Série legislação; n.81).

CAMPOS, L. M. S.; MELO, D. A. Indicadores de desempenho dos Sistemas de Gestão Ambiental (SGA): uma pesquisa teórica. Produção, v. 18, n. 3, set./dez. 2008. crossref

CNTL. Centro Nacional de Tecnologias Limpas SENAI-RS/UNIDO/UNEP. Implementação de Programas de Produção mais Limpa. Porto Alegre: CNTL, 2003(a).

CNTL. Centro Nacional de Tecnologias Limpas SENAI-RS/UNIDO/UNEP. Indicadores Ambientais e de Processo. Porto Alegre: CNTL, 2003(b).

CNTL. Centro Nacional de Tecnologias Limpas SENAI-RS/UNIDO/UNEP. Cinco fases da Implantação de Técnicas de Produção mais Limpa. Porto Alegre: CNTL, 2003(c).

CNTL. Centro Nacional de Tecnologias Limpas SENAI-RS/UNIDO/UNEP. Manual metodologia de implantação do programa de produção mais limpa. Curso de Consultores em Produção mais Limpa. Fortaleza: CNTL, 2002.

COELHO, A.; MACEDO, M. A.; VIDAL, L. N. L.; CORREIA, E. S. Avaliação de Desempenho Ambiental com base no conceito de Produção mais Limpa. In: 
International Workshop Advances in Cleaner Production, 2, 2009, São Paulo.

Anais eletrônicos... São Paulo: UNIP, 2009.

COELHO, H. M. G. Modelo para avaliação e apoio ao gerenciamento de resíduos sólidos de indústrias. 2011, 280 f. Tese (Doutorado em Saneamento, Meio Ambiente e Recursos Hídricos), Universidade Federal de Minas Gerais, Belo Horizonte, 2011.

COELHO, H. M. G.; LANGE, L. C.; JESUS, L. F. L.; SARTORI, M. R. Proposta de um Índice de Destinação de Resíduos Sólidos Industriais. Engenharia Sanitária e Ambiental, Rio de Janeiro, v.16, n.3, jul./set. 2011. crossref

FAGUNDES, A. B.; PEREIRA, D.; BEUREN, F. H.; CAMPOS, D. B.; SOUSA, A. L.; SILVA, M. C. Avaliação de desempenho ambiental de organizações com foco na gestão dos resíduos industriais: Uma contribuição à implementação da política nacional de resíduos sólidos. Espacios (Caracas), v. 37(25), p. 26, 2016. Disponível em <http://www.revistaespacios.com/a16v37n25/16372526.html>. Acesso em: 25 jul. 2018.

FAGUNDES, A. B.; SILVA, M. C.; MELLO, R. A gestão dos resíduos industriais em consonância com a Política Nacional de Resíduos Sólidos: Uma contribuição para as Micro e Pequenas Empresas. Espacios (Caracas), v. 36(1), p. 6, 2015. Disponível em < http://www.revistaespacios.com/a15v36n01/15360106.html>. Acesso em: 26 jul. 2018.

FEAM. Índice de produção mais limpa para a indústria de transformação do Estado de Minas Gerais. Caderno Técnico / Fundação Estadual do Meio Ambiente. Belo Horizonte: Feam, 2009. 99 p.

FIESP. Perguntas frequentes sobre Política Nacional de Resíduos Sólidos (PNRS). São Paulo: FIESP, 2012.

FIESP/CIESP. Cartilha Indicadores de Desempenho Ambiental na indústria. São Paulo: FIESP/CIESP, 2004.

GIANNETTI, B. F.; ALMEIDA, C. M. V. B. Ecologia Industrial: conceitos, ferramentas e aplicações. São Paulo: Edgard Blucher, 2006.

GIL, A. C. Como elaborar projetos de pesquisa. 4. ed., São Paulo: Atlas, 2002.

GOMES, F. C. S. P. Estímulo à Produção mais Limpa: contribuições para a discussão no Estado de São Paulo. (palestra proferida em 19 de agosto de 2010, na Sede da CETESB em São Paulo/SP, referente ao Índice P+L). Disponível em: < 
http://cetesb.sp.gov.br/consumosustentavel/documentos/ >. Acesso em: 22 jun. 2018.

LAKATOS, E. M.; MARCONI, M. A. Técnicas de Pesquisa. 6. ed., São Paulo: Atlas, 2006.

MENEZES, E. M.; SILVA, E. L. Metodologia da Pesquisa e Elaboração de

Dissertação. 4. ed., rev. Atual, Florianópolis: laboratório de ensino a distância da UFSC, 2005.

NEETZOW, R. F. W. Estímulo à Produção mais Limpa: contribuições para a discussão no Estado de São Paulo. (palestra proferida em 19 de agosto de 2010, na Sede da CETESB em São Paulo/SP, referente ao SAP+L). Disponível em: < http://cetesb.sp.gov.br/consumosustentavel/documentos/ >. Acesso em: 22 jun. 2018.

NEETZOW, R. F. W.; OLIVEIRA, J. M.; SOUZA, A. V. Sistema de Avaliação em Produção mais Limpa -SAPmaisL: Promovendo a Melhoria Contínua. In: International Workshop Advances in Cleaner Production, 2, 2009, São Paulo. Anais eletrônicos... São Paulo: UNIP, 2009.

OLIVEIRA, J. G.; BORGES, F. H.; JABBOUR, C. J. C. Avaliação de Desempenho no âmbito da Gestão Ambiental na organização. In: Simpósio de Engenharia de Produção, 12, 2005. Bauru. Anais eletrônicos... Bauru: UNESP, 2005.

RAUPP, F.; SELIG, P. M.; SIERRA, E. J. S. Determinação de indicadores de desempenho ambiental para as indústrias sucroalcooleiras. Revista Gestão Industrial, v.11, n.1, 2015. crossref

TAUCHEN, J.; BRANDLI, L. L. A Gestão Ambiental em Instituições de Ensino Superior: modelo para implantação em campus universitário. Gestão \& Produção. v.13, n.3, São Carlos, set-dez. 2006. crossref

VAN BELLEN, H. M. Indicadores de Sustentabilidade: uma análise comparativa. Rio de Janeiro: Editora FGV, 2006.

VAZ, C. R.; FAGUNDES, A. B.; OLIVEIRA, I. L. Diagnóstico ambiental inicial no setor produtivo de uma empresa de aluminio secundário pela ISO 14001 e pelo conceito da Produção Mais Limpa. Revista Gestão Industrial, v.5, n.4, 2009. crossref 
Recebido: 27 Jul. 2018

Aprovado: 10 Out. 2020

DOI: $10.3895 /$ gi.v16n2.8619

Como citar:

FAGUNDES, A. B., et al. Avaliação de Desempenho Ambiental com base nos conceitos da Produção mais Limpa: uma análise sobre três propostas metodológicas (SAPmaisL, Índice P+L e IDRSI. R. Gest. Industr., Ponta Grossa, v. 16, n. 2, p. 47-78, Abr./Jun. 2020. Disponivel em: https://periodicos.utfpr.edu.br/revistagi Correspondência:

Alexandre Borges Fagundes.

Rua Luiz Fernando Hastreiter, número180, Bairro Centenário, São Bento do Sul, SC, Brasil.

Direito autoral: Este artigo está licenciado sob os termos da Licença Creative Commons-Atribuição 4.0 Internacional.

(c) (1) 